\title{
Indefinite Integrals Involving Bessel Functions
}

\author{
B. A. Peavy
}

Institute for Applied Technology, National Bureau of Standards, Washington, D.C. 20234

(May 16, 1967)

Expressions are derived for the indefinite integrals,

$$
\begin{aligned}
& \int r f(r) C_{0}(\alpha r) d r \\
& \int r f(r) C_{0}^{2}(\alpha r) d r \\
& \int r f(r) C_{0}(\alpha r) C_{0}(\beta r) d r \quad \alpha \neq \beta \\
& \int r f(r) C_{0}(\alpha r) Z_{0}(\lambda r) d r
\end{aligned}
$$

where $C_{0}(\alpha r)$ are zero order Bessel functions, $Z_{0}(\lambda r)$ are zero order modified Bessel functions and $f(r)$ is a polynomial in $r$.In general, the expressions given for the integrals are given in terms of prescribed functions of the Bessel functions, and the coefficients of these functions are determined from a finite series, the terms of which are found from recurrence relationships that involve only the polynomial $f(r)$. Coefficients of the terms of the finite series are given in tabular form for up to an eleventh degree polynomial.

Key Words: Bessel functions, indefinite integrals.

\section{Introduction}

In this paper four indefinite integrals are studied; namely,

$$
\begin{aligned}
& \int r f(r) C_{0}(\alpha r) d r \\
& \int r f(r) C_{0}^{2}(\alpha r) d r \\
& \int r f(r) C_{0}(\alpha r) C_{0}(\beta r) d r \quad \alpha \neq \beta \\
& \int r f(r) C_{o}(\alpha r) Z_{0}(\lambda r) d r,
\end{aligned}
$$

where $f(r)$ is a $p$ th degree polynomial in $r$,

$$
f(r)=\sum_{n=0}^{p} a_{n} r^{n}
$$

$C_{0}(\alpha r)=A J_{0}(\alpha r)+B Y_{0}(\alpha r)$, and $Z_{0}(\lambda r)=D I_{0}(\lambda r)+E K_{0}(\lambda r) . J_{0}(\alpha r)$ and $Y_{0}(\alpha r)$ are zero order Bessel functions of the first and second kind, respectively, and $I_{0}(\lambda r)$ and $K_{0}(\lambda r)$ are zero order modified Bessel functions of the first and second kind, respectively. Expressions for integrals (1), (2), and (3) can be found in Watson [1] ${ }^{1}$ and Luke [2] which must be solved individually for every term of the polynomial $f(r)$ by rather cumbersome recursion formulas involving the Bessel functions. The expressions given here for the integrals are given in terms of prescribed functions

1 Figures in brackets indicate the literature references at the end of this paper. 
of the Bessel functions, and the coefficients of these functions are determined from a finite series, the terms of which are found from recurrence relationships that involve only the polynomial $f(r)$. Butler and Pohlhausen [3] have provided solutions of (1), (2), and (3) as definite integrals that specifically apply to solutions where $J_{0}(\alpha)=J_{0}(\beta)=0$. A more general application is needed. A method, not hitherto available in the literature, is presented here to enable a user to determine these indefinite integrals involving Bessel functions. Further comment in evaluation of the method is given at the end of the paper.

An example of the need for solutions to the integrals (1-4) is illustrated in the study of physical problems involving the steady-state diffusion process in a solid of cylindrical geometry, where a particular partial differential equation to be satisfied is

$$
\frac{\partial^{2} v}{\partial r^{2}}+\frac{1}{r} \frac{\partial v}{\partial r}+\frac{\partial^{2} v}{\partial z^{2}}=0
$$

$v$ is the potential, and $r$ and $z$ are the radial and longitudinal dimensions, respectively. A solution of (5) for the cylinder of finite length and outer radius is of the form

$$
v=C_{0}(\alpha r)\left\{\begin{array}{l}
\sinh \alpha z \\
\cosh \alpha z
\end{array}\right\}+Z_{0}(\lambda r)\left\{\begin{array}{l}
\sin \lambda z \\
\cos \lambda z
\end{array}\right\},
$$

where, for the solid cylinder $B=E=0$, or $C_{0}(\alpha r)=A J_{0}(\alpha r)$ and $Z_{0}(\lambda r)=D I_{0}(\lambda r)$, and final solution of (6) is dependent upon the evaluation of $A, B, D$, and $E$ from the boundary conditions on the curved and plane surfaces of the cylinder. For rather simple boundary conditions, the constants can readily be determined by use of the orthogonality properties of the Bessel and trigonometric functions.

More difficult boundary conditions on one or more of the plane and curved surfaces of the cylinder may take the general forms

$$
\begin{aligned}
& \frac{d v}{d z}=H(r)[v-V(r)] \text { on a plane surface } \\
& \frac{d v}{d r}=h(z)[v-V(z)] \text { on a curved surface }
\end{aligned}
$$

where the proportionality factors $H(r)$ and $h(z)$, and the potentials of the ambient $V(r)$ and $V(z)$ are position dependent. To obtain values for the constants of (6) upon the substitution of (6) and its first derivatives in (7) and (8), it would be convenient to use relationships such as

$$
\lambda \cos \lambda+h(0) \sin \lambda=0
$$

and

$$
\alpha C_{1}(\alpha)-H(0) C_{0}(\alpha)=0
$$

and their related orthogonality properties, and positive roots. For the determination of the constants $A$ and $B$ of (6), expressions are necessary for the integrals (1-4) with appropriate limits of integration assigned.

The reason for the specific boundary conditions cited above is to further and to ameliorate the study of radiant heat transfer and other nonlinear boundary conditions over nonisopotential surfaces in conjunction with heat conduction and other diffusion processes.

\section{Evaluation of $\int r f(r) C_{0}(\alpha r) d r$}

From expressions for the integral (1) for the special cases $f(r)=r^{m}, m=1,2,3$, and 4, derived by integration by parts, it can be shown by induction that a general expression for (l) is of the form

$$
\int r f(r) C_{0}(\alpha r) d r=\frac{r}{\alpha}\left[F(r) C_{1}(\alpha r)+\frac{F^{\prime}(r) C_{0}(\alpha r)}{\alpha}\right]-\frac{F^{\prime}(0)}{\alpha^{2}} \int C_{0}(\alpha r) d r
$$


where the polynomial $F(r)$ defined by this relation is to be determined in the subsequent analysis, and

$$
\begin{aligned}
C_{1}(\alpha r) & =A J_{1}(\alpha r)+B Y_{1}(\alpha r), \\
\int C_{0}(\alpha r) d r & =r C_{0}(\alpha r)+\frac{\pi}{2}\left[C_{1}(\alpha r) H_{0}(\alpha r)-C_{0}(\alpha r) H_{1}(\alpha r)\right] r
\end{aligned}
$$

and $H_{0}$ and $H_{1}$ are Struve functions of the first kind. Differentiation of (la) gives

$$
F^{\prime \prime}(r)+\frac{F^{\prime}(r)-F^{\prime}(0)}{r}+\alpha^{2} F(r)=\alpha^{2} F(r) \text {. }
$$

The differential equation (11) is satisfied by the following relationships:

$$
F(r)=f(r)+\sum_{n=2} \frac{(-1)^{n} P_{n}(r)}{\alpha^{2 n}}
$$

where for $n=1$

$$
P_{1}(r)=f^{\prime \prime}(r)+\frac{f^{\prime}(r)-f^{\prime}(0)}{r}
$$

and for $n>1$

$$
P_{n}(r)=P_{n-1}^{\prime \prime}(r)+\frac{P_{n-1}^{\prime}(r)-P_{n-1}^{\prime}(0)}{r} .
$$

In terms of the coefficients $a_{m}$ of a $p$ th degree polynomial

$$
\begin{gathered}
P_{n}=\sum_{m=2 n}^{p} a_{m} r^{m-2 n} R_{m, n} \\
R_{m, n}=\prod_{s=1}^{n}[m-2 s+2]^{2}, n \leqslant \frac{m}{2}
\end{gathered}
$$

Table 1 shows values of $R_{m, n}$ for values of $m$ from 1 to 11 . For the sake of example, let $f(r)=r^{7}$, then

$$
F(r)=r^{7}-\frac{49 r^{5}}{\alpha^{2}}+\frac{1225 r^{3}}{\alpha^{4}}-\frac{11,025 r}{\alpha^{6}}
$$

and

$$
F^{\prime}(r)=7 r^{6}-\frac{245 r^{4}}{\alpha^{2}}+\frac{3675 r^{2}}{\alpha^{4}}-\frac{11,025}{\alpha^{6}}
$$

are determined for substitution in (la).

TABLE 1. Values of $\mathrm{R}_{\mathrm{m}, \mathrm{n}}$

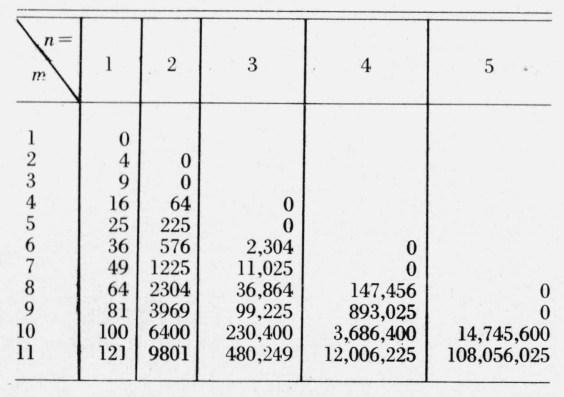


An interesting sidelight is the substitution of $Z_{0}(\lambda r)$ for $C_{0}(\alpha r)$ in (1a), which gives

$$
\int r f(r) Z_{0}(\lambda r) d r=\frac{r}{\lambda^{2}}\left[\lambda Z_{0}^{\prime}(\lambda r) F_{1}(r)-Z_{0}(\lambda r) F_{1}^{\prime}(r)\right]+\frac{F_{1}^{\prime}(0)}{\lambda^{2}} \int Z_{0}(\lambda r) d r
$$

where

$$
F_{1}(r)=f(r)+\sum_{n=1} \frac{P_{n}(r)}{\lambda^{2 n}}
$$

and $P_{n}(r)$ is as defined for (la).

\section{Evaluation of $\int r f(r) C_{0}^{2}(\alpha r) d r$}

An expression for (2) can be written in the form

$$
\begin{aligned}
\int r f(r) C_{0}^{2}(\alpha r) d r=\frac{r^{2}}{2}\left\{G(r)\left[C_{0}^{2}(\alpha r)+C_{1}^{2}(\alpha r)\right]+\right. & \frac{G^{\prime}(r)}{\alpha} C_{0}(\alpha r) C_{1}(\alpha r) \\
& \left.+\frac{1}{2 \alpha^{2}}\left[G^{\prime \prime}(r)+\frac{1}{r} G^{\prime}(r)\right] C_{0}^{2}(\alpha r)\right\}-\frac{G^{\prime}(0)}{4 \alpha^{2}} \int C_{0}^{2}(\alpha r) d r
\end{aligned}
$$

where the polynomial $G(r)$ is to be determined in the subsequent analysis. The integral $\int J_{0}^{2}(\alpha r) d r$ is given in (23), for $k=1$. Differentiation of both sides of (2a) gives

$$
r G^{\prime}(r)+G(r)=f(r)-\frac{1}{4 \alpha^{2}}\left[r G^{\prime \prime \prime}(r)+3 G^{\prime \prime}(r)+\frac{G^{\prime}(r)-G^{\prime}(0)}{r}\right] .
$$

The expression on the left can be written $r G^{\prime}(r)+G(r)=\frac{d}{d r}[r G(r)]$, then integration gives

$$
G(r)=\frac{1}{r} \int f(r) d r-\frac{1}{4 \alpha^{2} r} \int\left[r G^{\prime \prime \prime}(r)+3 G^{\prime \prime}(r)+\frac{G^{\prime}(r)-G^{\prime}(0)}{r}\right] d r .
$$

$G(r)$ is satisfied by

$$
G(r)=\sum_{n=0} \frac{(-1)^{n} S_{n}(r)}{\alpha^{2 n}}
$$

where for $n=0$

$$
S_{0}(r)=\frac{1}{r} \int f(r) d r
$$

and for $n>0$

$$
S_{n}(r)=\frac{1}{4 r} \int\left[r S_{n-1}^{\prime \prime \prime}(r)+3 S_{n-1}^{\prime \prime}(r)+\frac{S_{n-1}^{\prime}(r)-S_{n-1}^{\prime}(0)}{r}\right] d r .
$$

Also, (14) is satisfied for $G(r)$ in terms of the coefficients $a_{m}$ of a $p$ th degree polynomial by

$$
G(r)=\sum_{n=0}^{p / 2} \frac{(-1)^{n}}{(2 \alpha)^{2 n}} \sum_{m=2 n}^{p} a_{m} T_{m, n} r^{m-2 n}
$$

where

$$
T_{m, 0}=1 /(m+1), \text { and } T_{m, n}=\frac{1}{m+1} \prod_{s=1}^{n} \frac{(m-2 s+2)^{3}}{(m-2 s+1)}
$$


Values of $T_{m, n}$ are given in table 2 for $\mathrm{m}$ from 0 to 11 . For sake of example, let $f(r)=a_{0}+a_{1} r$ $+a_{2} r^{2}+a_{3} r^{3}+a_{4} r^{4}$, then from (15a) and table 2 ,

$$
G(r)=a_{0}+\frac{a_{1} r}{2}+\frac{a_{2} r^{2}}{3}+\frac{a_{3} r^{3}}{4}+\frac{a_{4} r^{4}}{5}-\frac{\frac{8 a_{2}}{3}+\frac{27 a_{3} r}{8}+\frac{64 a_{4} r^{2}}{15}}{(2 \alpha)^{2}}+\frac{512 a_{4}}{15(2 \alpha)^{4}}
$$

where the first and second differentials of $G(r)$ are necessary for substitution in (2a).

TABLE 2. Values of $\mathrm{T}_{\mathrm{m}, \mathrm{n}}$

\begin{tabular}{|c|c|c|c|c|c|c|}
\hline & 0 & 1 & 2 & 3 & 4 & 5 \\
\hline $\begin{array}{r}0 \\
1 \\
2 \\
3 \\
4 \\
5 \\
6 \\
7 \\
8 \\
9 \\
10 \\
11\end{array}$ & $\begin{array}{l}1 \\
1 / 2 \\
1 / 3 \\
1 / 4 \\
1 / 5 \\
1 / 6 \\
1 / 7 \\
1 / 8 \\
1 / 9 \\
1 / 10 \\
1 / 11 \\
1 / 12\end{array}$ & $\begin{array}{c}8 / 3 \\
27 / 8 \\
64 / 15 \\
125 / 54 \\
216 / 35 \\
343 / 48 \\
512 / 63 \\
729 / 80 \\
1000 / 99 \\
1331 / 120\end{array}$ & $\begin{array}{c}512 / 15 \\
1,125 / 16 \\
4,608 / 35 \\
42,875 / 192 \\
12,288 / 35 \\
83,349 / 160 \\
512,000 / 693 \\
323,433 / 320\end{array}$ & $\begin{array}{c}36,864 / 35 \\
385,875 / 128 \\
262,144 / 35 \\
2,083,725 / 128 \\
2,457,600 / 77 \\
37,979,173 / 640\end{array}$ & $\begin{array}{c}2,097,152 / 35 \\
5,2600,575 / 256 \\
52,428,800 / 77 \\
924,479,325 / 512\end{array}$ & $\begin{array}{c}419,430,400 / 77 \\
24,960,941,775 / 1024\end{array}$ \\
\hline
\end{tabular}

4. Evaluation of $\int r f(r) C_{0}(\alpha r) C_{0}(\beta r) d r, \alpha \neq \beta$

An expression for (3) may take the form

$$
\begin{gathered}
\int r f(r) C_{0}(\alpha r) C_{0}\left(\beta_{r}\right) d r=N_{1} U_{1}(r)+N_{2} U_{1}^{\prime}(r)-\gamma\left[N_{3} U_{2}(r)+N_{4} U_{2}^{\prime}(r)\right] \\
-\left[\psi U_{1}^{\prime}(0)-\gamma^{2} U_{2}^{\prime}(0)\right] \int C_{0}(\alpha r) C_{0}(\beta r) d r+\gamma\left[U_{1}^{\prime}(0)-\psi U_{2}^{\prime}(0)\right] \int C_{1}(\alpha r) C_{1}(\beta r) d r
\end{gathered}
$$

where

$$
\delta=\alpha^{2}-\beta^{2}, \psi=\left(\alpha^{2}+\beta^{2}\right) / \delta^{2}, \gamma=2 \alpha \beta / \delta^{2},
$$

$U_{1}(r)$ and $U_{2}(r)$ are polynomials to be determined in the subsequent analysis, and

$$
\begin{aligned}
N_{1} & =\int r C_{0}(\alpha r) C_{0}(\beta r) d r=\frac{r}{\delta}\left[\alpha C_{1}(\alpha r) C_{0}(\beta r)-\beta C_{0}(\alpha r) C_{1}(\beta r)\right] \\
N_{3} & =\int r C_{1}(\alpha r) C_{1}(\beta r) d r=\frac{r}{\delta}\left[\beta C_{1}(\alpha r) C_{0}(\beta r)-\alpha C_{0}(\alpha r) C_{1}(\beta r)\right] \\
N_{2} / r & =\psi C_{0}(\alpha r) C_{0}(\beta r)+\gamma C_{1}(\alpha r) C_{1}(\beta r) \\
N_{4} / r & =\psi C_{1}(\alpha r) C_{1}(\beta r)+\gamma C_{0}(\alpha r) C_{0}(\beta r)
\end{aligned}
$$

The integrals $\int J_{0}(\alpha r) J_{0}(\beta r) d r$ and $\int J_{1}(\alpha r) J_{1}(\beta r) d r$ are found in section 6 . Differentiation of both sides of (3a) gives the following equations: 


$$
\begin{gathered}
U_{1}(r)+\psi\left[U_{1}^{\prime \prime}(r)+\frac{U_{1}^{\prime}(r)-U_{1}^{\prime}(0)}{r}\right]-\gamma^{2}\left[U_{2}^{\prime \prime}(r)+\frac{U_{2}^{\prime}(r)-U_{2}^{\prime}(0)}{r}\right]=f(r) \\
U_{2}(r)+\psi\left[U_{2}^{\prime \prime}(r)-\frac{U_{2}^{\prime}(r)-U_{2}^{\prime}(0)}{r}\right]-\left[U_{1}^{\prime \prime}(r)-\frac{U_{d}^{\prime}(r)-U_{1}^{\prime}(0)}{r}\right]=0 .
\end{gathered}
$$

\section{Letting}

and

$$
U_{1}(r)=\sum_{k=0} \gamma^{2} k \sum_{n=0}(-1)^{n} \psi^{n} L_{k, n}(r)
$$

$$
U_{2}(r)=\sum_{k=0} \gamma^{2} k \sum_{n=0}(-1)^{n} \psi^{n} M_{k, n}(r)
$$

then substitution in (16) gives

$$
\begin{aligned}
& L_{0,0}(r)=f(r) \\
& L_{k, n}(r)=L_{k, n-1}^{\prime \prime}(r)+\frac{L_{k, n-1}^{\prime}(r)-L_{k, n-1}^{\prime}(0)}{r}+M_{k-1, n}^{\prime \prime}(r)+\frac{M_{k-1, n}^{\prime}(r)-M_{k-1, n}^{\prime}(0)}{r} \\
& M_{k, n}(r)=L_{k, n}^{\prime \prime}(r)-\frac{L_{k, n}^{\prime}(r)-L_{k, n}^{\prime}(0)}{r}+M_{k, n-1}^{\prime \prime}-\quad \frac{M_{k, n-1}^{\prime}(r)-M_{k, n-1}^{\prime}(0)}{r}
\end{aligned}
$$

\begin{tabular}{|c|c|c|c|c|c|c|c|c|c|c|c|c|}
\hline \multirow{2}{*}{$m$} & \multicolumn{6}{|c|}{ Coefficients of $a_{m}$ for $\gamma^{0}$} & \multicolumn{4}{|c|}{ Coefficients of $a_{m}$ for $\gamma^{2}$} & \multicolumn{2}{|c|}{ Coefficients of $a_{m}$ for $\gamma^{4}$} \\
\hline & $\begin{array}{l}r^{m} \\
L_{0,0}\end{array}$ & $\begin{array}{l}r^{m-2} \\
L_{0,1} \\
M_{0,0}\end{array}$ & $\begin{array}{l}r^{m-4} \\
L_{0,2} \\
M_{0,1}\end{array}$ & $\begin{array}{l}r^{m-6} \\
L_{0,3} \\
M_{0,2}\end{array}$ & $\begin{array}{l}r^{m-8} \\
L_{0,4} \\
M_{0,3}\end{array}$ & $\begin{array}{l}r^{m-10} \\
L_{0,5} \\
M_{0,4}\end{array}$ & $\begin{array}{l}r^{m-4} \\
L_{1,0}\end{array}$ & $\begin{array}{l}r^{m-6} \\
L_{1,1} \\
M_{1,0}\end{array}$ & $\begin{array}{l}r^{m-8} \\
L_{1,2} \\
M_{1,1}\end{array}$ & $\begin{array}{l}r^{m-10} \\
L_{1,3} \\
M_{1,2}\end{array}$ & $\begin{array}{l}r^{m-8} \\
L_{2,0}\end{array}$ & $\begin{array}{l}r^{m-10} \\
L_{2,1} \\
M_{2,0}\end{array}$ \\
\hline 0 & $\begin{array}{l}1 \\
0\end{array}$ & & & & & & & & & & & \\
\hline 1 & $\begin{array}{l}1 \\
0\end{array}$ & & & & & & & & & & & \\
\hline 2 & $\begin{array}{l}1 \\
0\end{array}$ & $\begin{array}{l}4 \\
0\end{array}$ & & & & & & & & & & \\
\hline 3 & $\begin{array}{l}1 \\
0\end{array}$ & $\begin{array}{l}9 \\
3\end{array}$ & & & & & & & & & & \\
\hline 4 & $\begin{array}{l}1 \\
0\end{array}$ & $\begin{array}{r}16 \\
8\end{array}$ & $\begin{array}{r}64 \\
0\end{array}$ & & & & $\begin{array}{r}32 \\
0\end{array}$ & & & ) & & \\
\hline 5 & $\begin{array}{l}1 \\
0\end{array}$ & $\begin{array}{l}25 \\
15\end{array}$ & $\begin{array}{l}225 \\
120\end{array}$ & & & & $\begin{array}{r}135 \\
0\end{array}$ & & & & & \\
\hline 6 & $\begin{array}{l}1 \\
0\end{array}$ & $\begin{array}{l}36 \\
24\end{array}$ & $\begin{array}{l}576 \\
480\end{array}$ & $\begin{array}{r}2,304 \\
0\end{array}$ & & & $\begin{array}{r}384 \\
0\end{array}$ & $\begin{array}{r}3,456 \\
0\end{array}$ & & & & \\
\hline 7 & $\begin{array}{l}1 \\
0\end{array}$ & $\begin{array}{l}49 \\
35\end{array}$ & $\begin{array}{l}1,225 \\
1,260\end{array}$ & $\begin{array}{r}11,025 \\
7,445\end{array}$ & & & $\begin{array}{r}875 \\
0\end{array}$ & $\begin{array}{r}19,215 \\
2,625\end{array}$ & & & & \\
\hline 8 & $\begin{array}{l}1 \\
0\end{array}$ & $\begin{array}{l}64 \\
48\end{array}$ & $\begin{array}{l}2,304 \\
2,688\end{array}$ & $\begin{array}{l}36,864 \\
39,936\end{array}$ & $\begin{array}{r}147,456 \\
0\end{array}$ & & $\begin{array}{r}1,728 \\
0\end{array}$ & $\begin{array}{l}70,656 \\
13,824\end{array}$ & $\begin{array}{r}442,368 \\
0\end{array}$ & & $\begin{array}{r}55,296 \\
0\end{array}$ & \\
\hline 9 & $\begin{array}{l}1 \\
0\end{array}$ & $\begin{array}{l}81 \\
63\end{array}$ & $\begin{array}{l}3,969 \\
5,040\end{array}$ & $\begin{array}{r}99,225 \\
135,135\end{array}$ & $\begin{array}{l}893,025 \\
703,080\end{array}$ & & $\begin{array}{r}3,087 \\
0\end{array}$ & $\begin{array}{r}203,175 \\
46,305\end{array}$ & $\begin{array}{r}3,044,790 \\
748,440\end{array}$ & & $\begin{array}{r}416,745 \\
0\end{array}$ & \\
\hline 10 & $\begin{array}{l}1 \\
0\end{array}$ & $\begin{array}{r}100 \\
80\end{array}$ & $\begin{array}{l}6,400 \\
8,640\end{array}$ & $\begin{array}{l}230,000 \\
360,960\end{array}$ & $\begin{array}{l}3,686,400 \\
4,730,880\end{array}$ & $\begin{array}{r}14,745,600 \\
0\end{array}$ & $\begin{array}{r}5,120 \\
0\end{array}$ & $\begin{array}{l}495,360 \\
122,880\end{array}$ & $\begin{array}{r}13,701,120 \\
4,945,920\end{array}$ & $\begin{array}{r}73,728,000 \\
0\end{array}$ & $\begin{array}{r}1,966,080 \\
0\end{array}$ & $\begin{array}{r}27,648,00 \\
0\end{array}$ \\
\hline 11 & $\begin{array}{l}1 \\
0\end{array}$ & $\begin{array}{r}121 \\
99\end{array}$ & $\begin{array}{r}9,801 \\
13,860\end{array}$ & $\begin{array}{l}480,249 \\
828,135\end{array}$ & $\begin{array}{l}12,006,225 \\
19,625,760\end{array}$ & $\begin{array}{r}108,056,025 \\
94,895,955\end{array}$ & $\begin{array}{r}8,019 \\
0\end{array}$ & $\begin{array}{r}1,072,071 \\
280,665\end{array}$ & $\begin{array}{l}47,505,150 \\
20,291,040\end{array}$ & $\begin{array}{l}604,178,190 \\
203,388,570\end{array}$ & $\begin{array}{r}7,016,625 \\
0\end{array}$ & $\begin{array}{r}245,768,985 \\
21,049,875\end{array}$ \\
\hline
\end{tabular}

where. negative subscripts denote zero quantities. In terms of the coefficients $a_{m}$ of a $p$ th order polynomial, the quantities of (17) have been evaluated for $m$ from zero to 11 in table 3 .

TABLE 3 


$$
\begin{array}{r}
U_{1}(r)=f(r)-\psi L_{0,1}+\psi^{2} L_{0,2}-\ldots .+\gamma^{2}\left[L_{1,0}-\psi L_{1,1}+\psi^{2} L_{1,2} \ldots\right]+\gamma^{4}\left[L_{2,0}-\psi L-\psi L_{2,1}\right. \\
+\ldots . .]
\end{array}
$$

$U_{2}(r)=M_{0,0}-\psi M_{0,1}+\psi^{2} M_{0,2}-\ldots .+\gamma^{2}\left[M_{1,0}-\psi M_{1,1}+\ldots\right]+\gamma^{4}\left[M_{2,0}-\psi M_{2,1}+\ldots\right.$.

From the table we get

$$
\begin{aligned}
& f(r)=r^{2} \quad U_{1}(r)=r^{2}-4 \psi \\
& U_{2}(r)=0 \\
& f(r)=r^{3} \quad U_{1}(r)=r^{3}-9 r \psi \\
& U_{2}(r)=3 r \\
& U_{1}(r)=r^{4}-16 r^{2} \psi+64 \psi^{2}+32 \gamma^{2} \\
& U_{2}(r)=8 r^{2} \\
& f(r)=r^{4} \quad \\
& U_{1}(r)=r^{5}-25 r^{3} \psi+225 r \psi^{2}+135 r \gamma^{2} \\
& U_{2}(r)=15 r^{3}-120 r \psi \\
& U_{1}(r)=r^{6}-36 r^{4} \psi+576 r^{2} \psi^{2}-2304 \psi^{4}+384 \gamma^{2} r^{2}-3456 \gamma^{2} \psi \\
& U_{2}(r)=24 r^{4}-480 r^{2} \psi \\
& f(r)=r^{6} U_{1}(r)=a_{0}+a_{1} r+a_{2} r^{2}+a_{3} r^{3}-\left(4 a_{2}+9 a_{3} r\right) \psi \\
& f(r)=a_{0}+a_{1} r+a_{2} r^{2}+a_{3} r^{3} \quad U_{2}(r)=3 a_{3} r .
\end{aligned}
$$

\section{Evaluation of $\int r f(r) C_{0}(\alpha r) Z_{0}(\lambda r) d r$}

An expression for (4) may take a form similar to (3a)

$$
\begin{aligned}
& \int r f(r) C_{0}(\alpha r) Z_{0}(\lambda r) d r=W_{1} V_{1}(r)-W_{2} V_{1}^{\prime}(r)+\gamma\left[W_{3} V_{2}(r)-W_{4} V^{\prime}(r)\right] \\
& +\left[\xi V_{1}^{\prime}(0)+\omega^{2} V_{2}^{\prime}(0)\right] \int C_{0}(\alpha r) Z_{0}(\lambda r) d r-\omega\left[V_{1}^{\prime}(0)+\xi V_{2}^{\prime}(0)\right] \int C_{1}(\alpha r) Z_{1}(\lambda r) d r
\end{aligned}
$$

where

$$
\begin{aligned}
& \phi=\alpha^{2}+\lambda^{2}, \xi=\left(\lambda^{2}-\alpha^{2}\right) / \phi^{2}, \omega=2 \alpha \lambda / \phi^{2} \\
& W_{1}=\int r C_{0}(\alpha r) Z_{0}(\lambda r) d r=\frac{r}{\phi}\left[\alpha C_{1}(\alpha r) Z_{0}(\lambda r)+\lambda C_{0}(\alpha r) Z_{1}(\lambda r)\right] \\
& W_{3}=\int r C_{1}(\alpha r) Z_{1}(\lambda r) d r=\frac{r}{\phi}\left[\lambda C_{1}(\alpha r) Z_{0}(\lambda r)-\alpha C_{0}(\alpha r) Z_{1}(\lambda r)\right] \\
& \frac{W_{2}}{r}=\xi C_{0}(\alpha r) Z_{0}(\lambda r)+\omega C_{1}(\alpha r) Z_{1}(\lambda r) \\
& \frac{W_{4}}{r}=\xi C_{1}(\alpha r) Z_{1}(\lambda r)-\omega C_{0}(\alpha r) Z_{0}(\lambda r)
\end{aligned}
$$

and

$$
Z_{1}(\lambda r)=D I_{1}(\lambda r)-E K_{1}(\lambda r) .
$$


An analysis similar to that of section (4) gives

$$
\begin{aligned}
& V_{1}(r)=\sum_{k=0}(-1)^{k} \omega^{2 k} \sum_{n=0} \xi^{n} L_{k, n}(r) \\
& V_{2}(r)=\sum_{k=0}(-1)^{k} \omega^{2 k} \sum_{n=0} \xi^{n} M_{k, n}(r)
\end{aligned}
$$

where $L_{k, n}(r)$ and $M_{k, n}(r)$ are as defined in section 4 and table 3.

$$
\text { 6. Evaluation of } \int J_{0}(\alpha r) J_{0}(\beta r) d r \text { and } \int J_{1}(\alpha r) J_{1}(\beta r) d r
$$

The expression for the first integral may be written in the form

$$
\int J_{0}(\alpha r) J_{0}(\beta r) d r=\int J_{0}(\alpha r) d r-\alpha^{2} \int r f(r) J_{0}(\alpha r) d r
$$

where from (la), the integral becomes

$$
\int J_{0}(\alpha r) J_{0}(\beta r) d r=\left[1+F^{\prime}(0)\right] \int J_{0}(\alpha r) d r-r\left[\alpha F(r) J_{1}(\alpha r) F^{\prime}(r) J_{0}(\alpha r)\right]
$$

and where

$$
f(r)=k^{2}\left[\frac{1-J_{0}(\beta r)}{\beta^{2} r}\right]=k^{2}\left(\frac{r}{2^{2}}-\frac{\beta^{2} r^{3}}{2^{2} \cdot 4^{2}}+\frac{\beta^{4} r^{5}}{2^{2} \cdot 4^{2} \cdot 6^{2}}-\ldots\right)
$$

is an infinite series and $k=\beta / \alpha<1$. From section $2, F(r)$ becomes

$$
F(r)=-\sum_{n=1}^{\infty} \frac{(-1)^{n} \alpha^{2(n-1)} r^{2 n-1}}{[1 \cdot 3 \cdot 5 \cdots(2 n-1)]^{2}} \sum_{m=n}^{\infty} \frac{\left(\frac{1}{2}\right)_{m}^{2} k^{2 m}}{(m !)^{2}}
$$

where $\left(\frac{1}{2}\right)_{m}=\Gamma\left(\frac{1}{2}+m\right) / \Gamma\left(\frac{1}{2}\right)$.

The complete elliptic integral of the first kind is defined

$$
K\left(k^{2}\right)=\int_{0}^{\pi / 2} \frac{d \varphi}{\left[1-k^{2} \sin ^{2} \varphi\right]^{1 / 2}}=\frac{\pi}{2} \sum_{m=0}^{\infty} \frac{\left(\frac{1}{2}\right)_{m}^{2} k^{2 m}}{(m !)^{2}} .
$$

The summation on $m$ in the above expression for $F(r)$ is then defined by

$$
L_{n}\left(k^{2}\right)=\frac{2}{\pi} K\left(k^{2}\right)-\sum_{m=0}^{n-1} \frac{\left(\frac{1}{2}\right)_{m}^{2} k^{2 m}}{(m !)^{2}} .
$$

The integral upon substitution becomes

$$
\begin{aligned}
& \int J_{0}(\alpha r) J_{0}(\beta r) d r=\frac{2}{\pi} K\left(k^{2}\right) \int J_{0}(\alpha r) d r \\
& \quad+\sum_{n=1}^{\infty} \frac{(-1)^{n} \alpha^{2(n-1)} r^{2 n-1}}{[1 \cdot 3 \cdot 5 \ldots \cdot(2 n-1)]^{2}} L_{n}\left(k^{2}\right)\left\{\alpha r J_{1}(\alpha r)+(2 n-1) J_{0}(\alpha r)\right\}
\end{aligned}
$$


where the integral $\int J_{0}(\alpha r) d r$ has been defined in section 2. The series is convergent for $k<1$. An expression for the integral $\int J_{0}(\beta r) Y_{0}(\alpha r) d r$ is found by substituting $Y_{0}(\alpha r), Y_{1}(\alpha r)$ for $J_{0}(\alpha r)$ and $J_{1}(\alpha r)$, respectively, in (22). An expression for the integral $\int J_{0}(\alpha r) I_{0}(\beta r) d r$ is found from (22) by substitution $k^{2}=-k^{2}, k^{2 m}=(-1)^{m} k^{2 m}$.

The expression (22) is limited for numerical evaluation due to a large loss of significance for large arguments although for values of $k^{2} \ll 1$ there is probably no restriction for numerical evaluation. Another more general expression for the integral can be obtained using the method of Butler and Pohlhausen [3, pp. 11-18]. An integral representation of the Bessel function is

$$
J_{0}(k r)=\frac{2}{\pi} \int_{0}^{1} \frac{\cos (k r t) d t}{\left(1-t^{2}\right)^{1 / 2}}=\frac{2}{\pi} \int_{\cos ^{-1} k}^{\pi / 2} \frac{\cos (r \cos \theta) \sin \theta d \theta}{\left(k^{2}-\cos ^{2} \theta\right)^{1 / 2}}
$$

where the expression on the right is derived from the substitution, $k t=\cos \theta$. A definite integral upon appropriate substitution becomes

$$
\begin{aligned}
\int_{0}^{y} J_{0}(\alpha r) J_{0}(\beta r) d r= & \frac{1}{\alpha} \int_{0}^{z} J_{0}(r) J_{0}(k r) d r \\
& =\frac{2}{\pi \alpha} \int_{\cos ^{1} k}^{\pi / 2} \frac{\sin \theta}{\left(k^{2}-\cos ^{2} \theta\right)^{1 / 2}} \int_{0}^{z} J_{0}(r) \cos (r \cos \theta) d r d \theta \\
& =y\left[J_{0}^{2}(z)+2 J_{1}^{2}(z)\right]+2 y J_{1}(z) \sum_{n=1}^{\infty} \frac{(-1)^{n} J_{2 n+1}(z)}{2 n+1} \Psi_{2 n+1} \\
& +y J_{0}(z) \sum_{n=1}^{\infty}(-1)^{n} J_{2 n}(z)\left[\frac{\Psi_{2 n-1}}{2 n-1}+\frac{\Psi_{2 n+1}}{2 n+1}\right]
\end{aligned}
$$

where $z=\alpha y$, and

$$
\Psi_{2 n+1}=\frac{2}{\pi} \int_{\cos ^{1} k}^{\pi / 2} \frac{\sin (2 n+1) \theta d \theta}{\left(k^{2}-\cos ^{2} \theta\right)^{1 / 2}}
$$

From [3, eq 55] values of $\Psi_{2 n+1}$ are determined by the recurrence formula

$$
\Psi_{m+2}=\frac{2 m\left(2 k^{2}-1\right)}{m+1} \Psi_{m}-\frac{m-1}{m+1} \Psi_{m-2}
$$

where $\Psi_{1}=1, \Psi_{3}=2 k^{2}-1, \Psi_{5}=6 k^{4}-6 k^{2}+1$, etc. The integral for $J_{0}^{2}(\alpha r) d r$ is found from (23) by setting $k=1$, whereby $\Psi_{2 n+1}=1$.

Numerical values for the definite integral

$$
\int_{0}^{1} J_{0}(\alpha r) J_{0}(\beta r) d r
$$

have been determined from (22) and (23) and are shown plotted against $k$ for various values of $\alpha$ in figure 1. For a few cases, the numerical values have also been obtained by numerical integration by Simpson's rule.

The expression for the second integral may be written by integration by parts in the form

$$
\int J_{1}(\alpha r) J_{1}(\beta r) d r=-\frac{J_{0}(\alpha r) J_{1}(\beta r)}{\alpha}+k \int J_{0}(\alpha r) J_{0}(\beta r) d r-k_{i} \int \frac{J_{1}(\beta r)}{\beta r} J_{0}(\alpha r) d r .
$$




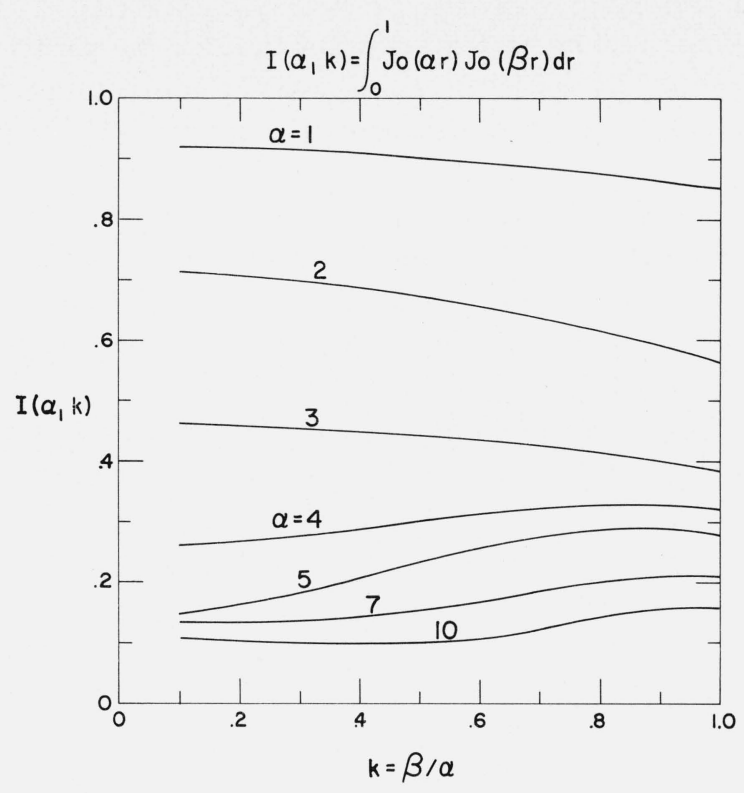

FigURE 1

The first integral on the right has been solved previously ((22) or (23)), and the second integral from (1a) takes the form

$\int \frac{J_{1}(\beta r)}{\beta r} J_{0}(\alpha r) d r$

$$
\begin{aligned}
& =\left[\frac{1}{2}+F^{\prime}(0)\right] \int J_{0}(\alpha r) d r-r\left[\alpha F(r) J_{1}(\alpha r)+F^{\prime}(r) J_{0}(\alpha r)\right] \\
& \quad \text { with } f(r)=k^{2} \frac{\beta r / 2-J_{1}(\beta r)}{\beta^{3} r}=k^{2}\left[\frac{r}{2^{2} \cdot 4}-\frac{\beta^{2} r^{3}}{2^{2} \cdot 4^{2} \cdot 6}+\frac{\beta^{4} r^{5}}{2^{2} \cdot 4^{2} \cdot 6^{2} \cdot 8}-\ldots\right] .
\end{aligned}
$$

From section 2, $F(r)$ becomes

$$
F(r)=-\sum_{n=1}^{\infty} \frac{(-1)^{n} \alpha^{2(n-1)} r^{2 n-1}}{[1 \cdot 3 \cdot 5 \cdots(2 n-1)]^{2}} \sum_{m=n}^{\infty} \frac{\left(\frac{1}{2}\right)_{m}^{2} k^{2 m}}{(m !)^{2}(2 m+2)}
$$

An integral of $K\left(k^{2}\right)$ is defined by

$$
\int_{0}^{k} k^{\prime} K\left(k^{\prime 2}\right) d k^{\prime}=E\left(k^{2}\right)-\left(1-k^{2}\right) K\left(k^{2}\right)=\frac{\pi}{2} \sum_{m=0}^{\infty} \frac{\left(\frac{1}{2}\right)_{m}^{2} k^{2 m+2}}{(m !)^{2}(2 m+2)}
$$

where $E\left(k^{2}\right)$ is the complete elliptic integral of the second kind. The summation on $m$ in the above expression for $F(r)$ is then defined by

$$
Q_{n}\left(k^{2}\right)=\frac{2}{\pi k^{2}}\left[E\left(k^{2}\right)-\left(1-k^{2}\right) K\left(k^{2}\right)\right]-\sum_{m=0}^{n-1} \frac{\left(\frac{1}{2}\right)_{m}^{2} k^{2 m}}{(m !)^{2}(2 m+2)} .
$$


The integral upon substitution becomes

$$
\begin{aligned}
\int J_{1}(\beta r) J_{1}(\alpha r) d r=-\frac{J_{0}(\alpha r) J_{1}(\beta r)}{\alpha}+\frac{2}{\pi k}\left[K\left(k^{2}\right)-E\left(k^{2}\right)\right] \int J_{0}(\alpha r) d r \\
+k \sum_{n=1}^{\infty} \frac{(-1)^{n} \alpha^{2(n-1)} r^{2 n-1}}{[1 \cdot 3 \cdot 5 \cdots(2 n-1)]^{2}} R_{n}\left(k^{2}\right)\left\{\alpha r J_{1}(\alpha r)+(2 n-1) J_{0}(\alpha r)\right\}
\end{aligned}
$$

where

$$
R_{n}\left(k^{2}\right)=\frac{2}{\pi k^{2}}\left[K\left(k^{2}\right)-E\left(k^{2}\right)\right]-\sum_{m=0}^{n-1} \frac{(2 m+1)\left(\frac{1}{2}\right)_{m}^{2} k^{2 m}}{(2 m+2)(m !)^{2}} .
$$

\section{Discussion}

An example of the usefulness of the method presented in this paper is given for the evaluation of the definite integral

$$
\int_{0}^{1} r f(r) J_{0}(\alpha r) d r
$$

where $f(r)=a_{0}+a_{2} r^{2}+a_{3} r^{3}+a_{4} r^{4}$. The integral is of the form given in (la), where the coefficients of the polynominal $F(r)$ are given in table 1. The resulting expressions for the upper limit are

$$
\begin{aligned}
& F(1)=f(1)-\frac{4 a_{2}+9 a_{3}+16 a_{4}}{\alpha^{2}}+\frac{64 a_{4}}{\alpha^{4}} \\
& F^{\prime}(1)=f^{\prime}(1)-\frac{9 a_{3}+32 a_{4}}{\alpha^{2}}, \text { and } \\
& F^{\prime}(0)=-\frac{9 a_{3}}{\alpha^{2}} .
\end{aligned}
$$

From (la), the definite integral (25) becomes

$$
\int_{0}^{1} r f(r) J_{0}(\alpha r) d r=\frac{F(1) J_{1}(\alpha)}{\alpha}+\frac{F^{\prime}(1) J_{0}(x)}{\alpha^{2}}+\frac{9 a_{3}}{\alpha^{4}} \int_{0}^{1} J_{0}(\alpha r) d r
$$

where the integral on the right is evaluated using (lb). Given values for $a_{0}, a_{2}, a_{3}, a_{4}$, and $\alpha$, and tables of Bessel and Struve functions, the value of the definite integral is readily computed by desk calculator. If subroutines are available for computing the Bessel and Struve functions, digital computer calculation is rapidly accomplished.

In this instance, the value of the definite integral is determined with need only for evaluation of $F(r)$, using table 1 , and then of $F(1), F^{\prime}(1), F^{\prime}(0)$, and of four additional functions, namely, $J_{0}(\alpha), J_{1}(\alpha), H_{0}(\alpha)$ and $H_{1}(\alpha)$. The computational task is minor as compared with that of evaluating many subdivisions or steps of the original integrand for a numerical integration of equivalent accuracy.

\section{References}

[1] G. N. Watson, A treatise on the theory of Bessel functions, (Cambridge University Press, 1948).

[2] Y. L. Luke, Integrals of Bessel functions, (McGraw-Hill Book Co., New York, N.Y., 1962).

[3] T. Butler and K. Pohlhausen, Tables of definite integrals involving Bessel functions of the first kind, (WADC Technical Report 54-420, Wright Air Development Center, Wright Patterson Air Force Base, Ohio, 1954).

(Paper 71B2\&3-207) 


\section{Publications of the National Bureau of Standards *}

\section{Selected Abstracts}

Hadamard matrices of order cube plus one, K. Goldberg, Proc. Am. Math.Soc. 1 7, No. 3, 744-746 (June 1966).

If $H$ is an Hadamard matrix of order $h$, with the property that $H+H^{T}=2 I$, then there exists an Hadamard matrix of order $(h-1)^{3}$ +1 with the same property.

A functional inequality, S. Haber, Am. Math. Mo. 73, No. 10, 1103-1104 (Dec. 1966).

It is shown that if $f$ is a continuous increasing function then $f(x)$ $\cdot f^{-1}(x)>(1-\epsilon) x^{2}$, for some sets of values of $x$.

\section{Other NBS Publications}

J. Res. NBS 71 A (Phys. and Chem.), No. 2 (Mar.-Apr. 1967), $\$ 1.00$.

Relative enthalpy of beryllium 1:1-aluminate, $\mathrm{BeO} \cdot \mathrm{Al}_{2} \mathrm{O}_{3}$, from 273 to $1173{ }^{\circ} \mathrm{K}$. Thermodynamic properties from 273 to $2150{ }^{\circ} \mathrm{K}$. D. A. Ditmars and T. B. Douglas.

Relative enthalpy of beryllium 1:3-aluminate, $\mathrm{BeO} \cdot 3 \mathrm{Al}_{2} \mathrm{O}_{3}$, from 273 to $1173^{\circ} \mathrm{K}$. Thermodynamic properties from 273 to $2150{ }^{\circ} \mathrm{K}$. D. A. Ditmars and T. B. Douglas.

The heats of combustion of polytetrafluoroethylene (Teflon) and graphite in elemental fluorine. E. S. Domalski and G. T. Armstrong.

Phase relations in the systems $\mathrm{TiO}_{2}-\mathrm{IrO}_{2}$ and $\mathrm{SnO}_{2}-\mathrm{IrO}_{2}$ in air. C. L. McDaniel and S. J. Schneider.

Sample purity and the N.Q.R. of $\mathrm{Cl}^{35}$ in $\mathrm{KClO}_{3}$ at $0{ }^{\circ} \mathrm{C}$. D. B. Utton.

Techniques for the growth of large single crystals of potassium of high purity. H. J. Foster and P. H. E. Meijer.

Synthesis of $\alpha$-L-fucose-l; ${ }^{14} \mathrm{C} \quad$ (6-deoxy-L-galactose-1-14 C. H. S. Isbell, H. L. Frush, and N. B. Holt.

Deuterium isotopes effects in $\alpha-\beta$ in the pyranose-furanose interconversions. H. S. Isbell and C. W. R. Wade.

Calculated transition strengths between the configurations $5 d^{8} 6 s$ and $5 d^{8} 6 p$ in Au III. H. Mendolwitz.

Hartree-Fock multiplet strengths for KI, CaII, and ScIII. A. W. Weiss.

Oscillator strengths for the helium isoelectronic sequence. A. W. Weiss.

Solvent effects on the ultraviolet absorption of polystyrene. V. M. Story, D. McIntyre, and J. H. O’Mara.

\section{J. Res. NBS 71 A (Phys. and Chem.), No. 3 (May-June 1967),} $\$ 1.00$.

Measured relative enthalpy of anhydrous crystalline aluminum trifluoride, $\mathrm{AlF}_{3}$, from 273 to $1173^{\circ} \mathrm{K}$ and derived thermodynamic properties from 273 to $1600{ }^{\circ} \mathrm{K}$. T. B. Douglas and D. A. Ditmars.

The heat of formation of boron trifluoride by direct combination of the elements. E. S. Domalski and G. T. Armstrong.

An equation of state for fluid parahydrogen from the triple-point to $100{ }^{\circ} \mathrm{K}$ at pressures to 350 atmospheres. R. D. Goodwin.

The dissociation constants of some disubstituted anilines and phenols in aqueous solution at $25{ }^{\circ} \mathrm{C}$. R. A. Robinson.

Third virial coefficient for air-water vapor mixtures. R. W. Hyland and E. A. Mason.

Recrystallization and melting of partially melted stark rubber. Donald E. Roberts.

Effects of a distribution of volume relaxation times in the annealing of BSC glass. P. B. Macedo and A. Napolitano.
J. Res. NBS $71 \mathrm{C}$ (Engr. and Instr.), No. 1 (Jan.-Mar. 1967), 75 cents.

Dedication of the new NBS laboratories.

Symmetrical bending of thin circular elastic plates on equally spaced point supports. A. F. Kirstein and R. M. Woolley.

Ultrasonic measurement of cylinder expansion at pressures to 40 kilobars. P. L. M. Heydemann and J. C. Houck.

A comparison of absorbed dose determinations in graphite by cavity ionization measurements and by calorimetry. B. Petree and P. Lamperti.

Germanium resistance thermometry in the range 2.1 to $5.0^{\circ} \mathrm{K}$. M. H. Edlow and H. H. Plumb.

Least squares technique for the analysis of periodic temperatures of the earth's surface region. T. Kusuda.

A new near-zone electric-field-strength meter. F. M. Greene.

Inductance and characteristic impedance of a strip-transmission line. R. L. Brooke, C. A. Hoer, and C. H. Love.

Tensor permeability measurements at L-band frequencies using a degenerate mode cavity. L. B. Schmidt, R. D. Harrington, and W. E. Case.

J. Res. NBS 71 C (Engr. and Instr.), No. 2 (Apr.-June 1967), 75 cents.

An apparatus for measuring thermal expansion at elevated temperatures. B. D. Rothrock and R. K. Kirby.

Determination and smoothing of Fourier coefficients representing piecewise continuous functions. B. A. Peavy.

A $2: 1$ ratio inductive voltage divider with less than $0.1 \mathrm{ppm}$ error to $1 \mathrm{MHz}$. C. A. Hoer and W. L. Smith.

A dual-load flow calorimeter for $\mathrm{rf}$ power measurement to $4 \mathrm{GHz}$. M. L. Crawford and P. A. Hudson.

Polymeric materials for dielectric reference specimens. A. H. Scott and J. R. Kinard, Jr.

The sensitivity of the Dicke radiometer. D. F. Wait.

Sensivity of a correlation radiometer. J. J. Faris.

Heat treatment and properties of iron and steel, T. G. Digges, S. J. Rosenberg, and G. W. Geil, Mono. 88 (Nov. 1, 1966) u cents. (Supersedes Circular 495 and Monograph 18).

Microwave attenuation measurements and standards, R. W. Beatty, Mono. 97 (Apr. 3, 1967), 25 cents.

Abscissas and weights for Gaussian Quadrature for $N=2$ to 100 , and $N=125,150,175,200$, C. H. Love, Mono. 98 (Dec. 28, 1966), 55 cents.

ASTM metric practice guide, Handb. 102 (Mar. 10, 1967), 40 cents.

Standard Reference Materials: Viscosity of a standard lead-silica glass, A. Napolitano and E. G. Hawkins, Misc. Publ. 260-11 (Nov. 7, 1966), 25 cents.

Legibility of alphanumeric characters and other symbols. II. A reference handbook, D. Y. Cornog and F. C. Rose, Misc. Publ. 262-2 (Feb. 10, 1967), \$4.25.

Critical Phenomena. Proceedings of a Conference held in Washington, D.C., April 1965, ed. M. S. Green and J. V. Sengers, Misc. Publ. 273 (Dec. 1, 1966), \$2.50.

Bibliography on flame spectroscopy. Analytical applications 1800 to 1966, R. Mavrodineanu, Misc. Publ. 281 (Feb. 23, 1967), \$2.00.

The National Bureau of Standards 1966, Misc. Publ. 282 (Nov. 1966), 35 cents.

Bibliography of low energy electron collision cross section data, L. J. Kieffer, Misc. Publ. 289 (Mar. 10, 1967), 50 cents. 
Tables of molecular vibrational frequencies Part 1, T. Shimanouchi, NSRDS-NBS 6 (Mar. 1, 1967), 40 cents.

Thermal conductivity of selected materials, R. W. Powell, C. Y. Ho, and P. E. Liley, NSRDS-NBS 8 (Nov. 25, 1966), \$1.00.

Cast-iron radiators, R174-65 (Dec. 31, 1965), 10 cents. Supersedes R174-47.

Standard sizes of blackboard slate, Prod. Std. 2-66 (May 15, 1966), 10 cents. Supersedes SPR15-35.

TFE-Fluorocarbon (polytetrafluoroethylene) resin skived tape, Prod. Std. 3-66 (Sept. 1, 1966), 10 cents.

Porcelain enameled formed steel plumbing fixtures, Prod. Std. 5-66, (Nov. 1, 1966), 15 cents. Supersedes CS144-47.

Trim for water-closet bowls, tanks and urinals (dimensional standards), Prod. Std. 6-66 (Nov. 1, 1966), 10 cents. Supersedes CS172-50.

Wire bar supports for reinforced concrete construction, Prod. Std. 7-66 (Aug. 1, 1966), 10 cents.

Scanning electron probe microanalysis, K. F. J. Heinrich, Tech. Note 278 (Feb. 3, 1967), 30 cents.

Procedures for precise determination of thermal radiation properties, November 1964 to October 1965, J. C. Richmond, G. J. Kneissl, D. L. Kelley, and F. J. Kelly, Tech. Note 292 (Feb. 10, 1967), 50 cents.

Notes on the state-of-the-art of benefit-cost analysis as related to transportation systems, J. D. Crumlish, Tech. Note 294 (Nov. 1, 1966), 30 cents.

A grammar for component combination in Chinese characters, B. K. Rankin, III, S, Siegel, A. McClelland and J. L. Tan, Tech. Note 296 (Dec. 1966), 60 cents.

A survey of ionization vacuum gages and their performance characteristics, W. G. Brombacher, Tech. Note 298, (Feb. 3, 1967), 40 cents.

Calculation of the heating value of a sample of high purity methane for use as a reference material, G. T. Armstrong, Tech. Note 299 (Dec. 15, 1966), 25 cents.

A new near-zone electric field-strength meter, F. M. Greene, Tech. Note 345 (Nov. 15, 1966), 35 cents.

A standard for accurate phase-angle measurements at audio frequencies, W. W. Scott, Jr., Tech. Note 347 (Oct. 14, 1966), 25 cents.

Infrared reflectances of metals at cryogenic temperatures - a compilation from the literature, P. F. Dickson and M. C. Jones, Tech. Note 348 (Oct. 14, 1966), 40 cents.

The design and operation of a high voltage calibration facility, W. W. Scott, Jr., Tech. Note 349 (Nov. 10, 1966), 25 cents.

Radiochemical analysis: activation analysis, instrumentation, radiation techniques, and radioisotope techniques July 1965 through June 1966, ed. J. R. DeVoe, Tech. Note 404 (Sept. 30, 1966), \$1.25.

Fortran programs for the calculation of Wigner $3 j, 6 j$, and $9 j$ coefficients for angular momenta $\leqslant 80$, Tech. Note 409 , R. S. Caswell and L. C. Maximon, (Nov. 15, 1966), 40 cents.

Methods for performance-testing of electromechanical pressure transducers, P. S. Lederer, Tech. Note 411 (Feb. 9, 1967), 25 cents.

Abstraction of hydrogen atoms from isobutane- $d_{9}$ by methylene, M. L. Halberstadt and J. R. McNesby, J. Chem. Phys. 45, No. 5 , 1666-1669 (Sept. 1, 1966).

Chemisorption of nitric oxide on tungsten, J. T. Yates, Jr., and T. E. Madey, J. Chem. Phys. 45, No. 5, 1623-1634 (Sept. 1, 1966).

Dissociation constant of morpholinum ion and related thermodynamic quantities from 0 to $50^{\circ}$, H. B. Hetzer, R. G. Bates, and R. A. Robinson, J. Phys. Chem. 70, No. 9, 2869-2872 (Sept. 1966).

Dissociation of 4-aminopyridinium ion in 50 percent methanolwater and related acidity functions from 10 to $40{ }^{\circ} \mathrm{C}$, M. Paabo, R. A. Robinson, and R. G. Bates, Anal. Chem. 38, No. 11, 15731575 (Oct. 1966).

Electron affinity of tungsten determined by its positive and negative self-surface ionization, M. D. Scheer and J. Fine, Phys. Rev. Letters 17, No. 6, 283-284 (Aug. 8. 1966).

Kinetics and statistics of structural changes in polyacrylonitrile, K. Noh and H. Yu, J. Polymer Sci. Letters 4B, No. 10, 72l-726 (Oct. 1966).

Mass-spectrometric investigation of the nickel-fluorine surface reaction, J. D. McKinley, J. Chem. Phys. 45, No. 5, 1690-1693 (Oct. 1, 1966).

Mass-spectrometric study of the rate of the reaction $\mathrm{CO}+\mathrm{OH}$, J. T. Herron, J. Chem. Phys. 45, No. 5, 1854-1855 (Sept. 1, 1966).
Matrix-isolation study of the photolysis of cyanogen azide. II. The symmetric stretching fundamental of the free radical NCN, D. E. Milligan and M. E. Jacox, J. Chem. Phys. 45, No. 5, 13871391 (Sept. 1, 1966).

Momentum autocorrelation function for systems with finite spatial boundaries, R. Nossal, J. Chem. Phys. 45, No. 4, 1097-1100 (Aug. 15, 1966).

Pseudonatural orbitals as a basis for the superposition of configurations. I. $\mathrm{He}_{2}^{+}$, C. Edmiston and M. Krauss, J. Chem. Phys. 45 , No. 5, 1833-1839 (Sept. 1, 1966).

Translational diffusion in polymer solutions, R. Zwanzig, J. Chem. Phys. 45, No. 5, 1858-1859 (Sept. 1, 1966).

A device for use in applying strain gages to cylindrical specimens, T. W. Butler and R. L. Bloss, Experimental Mechanics 6, No. 10, 528 (Oct. 1966).

A simplified method for the prediction of multi-component adsorption equilibria from single gas isotherms, A. J. Kidnay and A. L. Myers, AIChE J. 12, No. 5, 981-986 (Sept. 1966).

Calibration and use of laminar flowmeters, H. H. Allion, (Proc. 25th Annual Gas Measurement Short Course, Aug. 25, 1965), West Virginia Univ. Tech. Bull 77, pp. 34-43 (1965).

Coincident summer weather characteristics of six selected cities in the United States, T. Kusuda and P. R. Achenbach, ASHRAE J. 8, No. 11, 34-42 (Nov. 1966).

Embrittlement of high strength AISI 4340 steel in boiling $\mathrm{NaCl}$ solution, H. L. Logan and J. M. Wehrung, Corrosion 22, No. 9 , 265-269 (Sept. 1966).

Some effects of notch geometry on the tensile behavior of annealed type 310 stainless steel, G. W. Geil, J. Materials 1, No. 3, 583-608 (Sept. 1966)

Monte Carlo studies of lattice-model polymer chains. I. Correlation functions in the statistical-bead model, P. H. Verdier, J. Chem. Phys. 45, No. 6, 2118-2121 (Sept. 15, 1966).

Monte Carlo studies of lattice-model polymer chains. II. End-to-end length, P. H. Verdier, J. Chem. Phys. 45, No. 6, 2122-2128 (Sept. 15, 1966).

A nonmagnetic laboratory for the National Bureau of Standards, F. K. Harris, IEEE Spectrum 3, No. 11, 85-87 (Nov. 1966).

A scattering chamber for use with cooled large area lithium-compensated silicon radiation detectors, W. R. Dodge, J. A. Coleman, and S. R. Domen, Nucl. Instr. Methods 42, 181-187 (July 1966).

A zero-range treatment of the three-body photodisintegration cross section of ${ }^{3} \mathrm{H}$ and ${ }^{3} \mathrm{He}$, J. M. Knight, J. S. O'Connell, and F. Prats, Phys. Letters 22, No. 3, 322-325 (Aug. 15, 1966).

Anomalous energy spreads in electron beams, J. A. Simpson and C. E. Kuyatt, J. Appl. Phys. 37, No. 10, 3805-3809 (Sept. 1966).

Bandlike structure from continuum-continuum emission: the $\mathrm{He}$ 600- $\AA$ bands, F. H. Mies and A. L. Smith, J. Chem. Phys. 45, No. 3, 994-1000 (Aug. 1, 1966).

Classification of the $Y_{1}(1765)$ and $Y_{0}(1520)$ resonances in the 1134 representation of SU(6), J. J. Coyne, S. Meshkov, and G. B. Yodh, Phys. Rev. Letters 17, No. 12, 666-668 (Sept. 19, 1966).

Determination of the effective force constants between a substitutional impurity and its nearest neighbors in an alkali halide crystal, R. A. MacDonald, Phys. Rev. 150, No. 2, 597-602 (Oct. $14,1966)$.

Dielectric constants of $\mathrm{PbMoO}_{4}$ and $\mathrm{CaMoO}_{4}$, W. S. Brower and P. H. Fang, Phys. Rev. 149, No. 2, 646 (Sept. 16, 1966).

Effect of surface patch fields on field-emission work-function determinations, R. D. Young and H. E. Clark, Phys. Rev. Letters 17, No. 7, 351-353 (Aug. 15, 1966).

EPr in single crystals of $\mathrm{NiBr}_{2}, \mathrm{~J}$. S. Wells and D. R. Winder, J. Chem. Phys. 45, No. 1, 410-411 (July 1, 1966).

Erratum: Statistical model for the beta zirconium hydrides, T. B. Douglas, J. Chem. Phys. 45, No. 3, 1080 (Aug. 1, 1966).

Lithium compensated silicon focal plane detectors for electron scattering spectrometers, W. R. Dodge, J. A. Coleman, S. R. Domen, and J. K. Whittaker, Rev. Sci. Instr. 37, No. 9, 1151-1159 (Sept. 1966).

Measurement of the mean energy required to create an electronhole pair in silicon between 6 and $77^{\circ} \mathrm{K}, \mathrm{W}$. R. Dodge, S. R. Domen, T. F. Leedy, and D. M. Skopik, Phys. Rev. Letters 17, No. 12, 653-655 (Sept. 19, 1966).

Microwave spectrum of $\mathrm{CF}_{2}, \mathrm{~F}$. X. Powell, and D. R. Lide, Jr., J. Chem. Phys. 45, No. 3, 1067-1068 (Aug. 1, 1966). 
Motions of water molecules in potassium ferrocyanide trihydrate, water, and ice: a neutron scattering study, J. J. Rush, P. S. Leung, and T. I. Taylor, J. Chem. Phys. 45, No. 4, 1312-1317 (Aug. 15, 1966).

Multiple diffraction in the Weissenberg methods, A. Santoro and M. Zocchi, Acta Cryst. 21, pt. 3, 293-297 (Sept. 1966).

Photodetachment cross section, electron affinity and structure of the negative hydroxyl ion, L. M. Branscomb, Phys. Rev. 148, No. 1, 11-18 (Aug. 5, 1966).

The structure of field-evaporated hexagonal close-packed surfaces: rhenium and ruthenium, A. J. Melmed, Surface Science 5, No. 3, 359-379 (Nov. 1966).

Zeeman effect and magnetic hyperfine structure in the low frequency transitions of $\mathrm{H}_{2} \mathrm{CO}, \mathrm{H}$. Takuma, K. M. Evenson, and T. Shigenari, J. Phys. Soc. 21, 1622-1623 (1966).

Acidity functions for amphiprotic media, R. G. Bates, Book, Chemistry of Nonaqueous Solvents, I, sec. III, 97-128 (Academic Press Inc., New York, N.Y., 1966).

Collagen aggregation phenomena, J. M. Cassel, Biopolymers 4, 989-997 (1966).

Effect of certain crystalline substances on physical properties of elastomers. I. Stress-strain behavior, F. J. Linnig, E. J. Parks, and R. D. Stiehler, Rubber Chem. Technol. 39, No. 4, pt. 1, 1041-1052 (Sept. 1966).

Oxidation products in an oxygen-blown Kuwait asphalt, P. G. Campbell and J. R. Wright, I\&EC Product Res. Devel. 5, No. 4, 319323 (Dec. 1966).

Proton broad-line N.m.r. study of $\left({ }^{2} \mathrm{H}_{6}\right)$ dimethoxy $\left({ }^{11} \mathrm{~B}\right)$ borane, T. C. Farrar, J. Cooper, and T. D. Coyle, Chem. Commun. 17, 610-611 (1966)

Studies of molten alumina in the arc-image furnace, J. J. Diamond and A. L. Dragoo, Rev. Hautes Temper. et Refract. 3, 272-279 (1966).

The adsorption kinetics of nitrogen on rhenium, M. D. Scheer and J. D. McKinley, Surface Sci. 5, No. 3, 332-344 (Nov. 1966).

The melting point of $\mathrm{Al}_{2} \mathrm{O}_{3}$ in vacuum, S. J. Schneider and C. L. McDaniel, Rev. Hautes Temper. et Refract. 3, 351-361 (1966).

Temperature measurement in high temperature chemistry: 1000$3000{ }^{\circ} \mathrm{C}$, R. F. Walker, Rev. Hautes Temper. et Refract. 3, 301308 (1966).

An ultrasonic pressure gage, P. L. M. Heydemann, Am. Soc. Mech. Eng. Publ. No. 66-WA/PT-5 (1966).

Government, industry and engineering. NBS in a new setting, S. Lichtenstein, Automotive Ind. 135, No. 10, 119-124 (Nov. 15, 1966).

Progress in nuclear electronics, L. Costrell, Book, Radioisotopes for Aerospace, Part 1. Advances and Techniques, p. 1-13 (Plenum Press Inc., New York, N.Y., 1966).

State standards and laboratories, T. M. Stabler, Scale J. 53, No. 1, 3-14 (Oct. 1966).

The measurement of solar radiation, with principal emphasis on the ultraviolet component, R. Stair, Air Water Pollut. Int. J. 10, 665-688 (1966).

Accurate microscopical determination of optical properties on one small crystal, C. P. Saylor, Book, Advances in Optical and Electron Microscopy, ed. R. Barer and V. E. Cosslett, 1, 4l-76 (Academic Press Inc., New York, N.Y., 1966).

Angle and channel dependence of resonance in e-He scattering near $60 \mathrm{eV}$, J. A. Simpson, M. G. Menendez, and S. R. Mielczarek, Phys. Rev. 150, No. 1, 76-78 (Oct. 7, 1966).

Anomalous work function of the tungsten (110) plane, R. D. Young and H. E. Clark, Appl. Phys. Letters 9, No. 7, 265-268 (Oct. 1, 1966).

Compressibility, gas, J. M. H. L. Sengers, Encyclopedia of Physics, p. 118-120 (Reinhold Publ. Corp., New York, N.Y., 1966).

Effect of nuclear alinement on the $14-\mathrm{MeV}$ total neutron cross section of ${ }^{165} \mathrm{Ho}, \mathrm{H}$. Marshak, A. C. B. Richardson, and T. Tamura, Phys. Rev. 150, No. 3, 996-1010 (Oct. 21, 1966).

Electron microscopy and diffraction of synthetic corundum crystals. II. Dislocations and grain boundaries in impurity-doped aluminum oxide, D. J. Barber and N. J. Tighe, Phil. Mag. 14, No. 129, 531-544 (Sept. 1966).

Exact vibrational matrix elements for molecular hydrogen and the intensity of the quadrupole rotation-vibration spectrum, T. C. James, Astrophys. J. 146, No. 2, 572-580 (Nov. 1966).
Interference in the photoionization of molecules, H. D. Cohen and U. Fano, Phys. Rev. 150, No. 1,30-33 (Oct. 7, 1966).

Pyrometry, optical, H. J. Kostkowski, Encyclopedia of Physics, p. 563-564 (Reinhold Publ. Corp., New York, N.Y., 1966).

Resonances in inelastic electron scattering from $\mathrm{H}_{2}$, M. G. Menendz and H. K. Holt, J. Chem. Phys. 45, No. 8, 2743-2744 (Oct. 15, 1966).

The $A^{\prime} \Sigma$ transition of ${ }^{39} \mathrm{KH}$ and ${ }^{39} \mathrm{KD}$. Vibrational numbering and molecular constants, I. R. Bartky, J. Mol. Spectry. 20, No. 4, 299-311 (1966).

The absorption spectrum of cesium deuteride. The $\mathrm{A}^{1} \Sigma$ state of CsH, I. R. Bartky, J. Mol. Spectry. 21, No. 1, 25-28 (1966).

The absorption spectrum of RbD. Vibrational numbering of the $\mathrm{A}^{1} \Sigma$ state of RbH, I. R. Bartky, J. Mol. Spectry. 21, No. 1, 1-3, (1966).

The momentum autocorrelation function in a Bernoulli chain, R. J. Rubin and P. Ullersma, J. Math. Phys. 7, No. 10, 1877-1885 (Oct. 1966).

What environment-for whom? G. E. Auman, Civil Service J. 7, No. 1, 6-11 (July-Sept. 1966).

X-ray fiber optics, L. Marton, Appl. Phys. Letters 9, No. 5, 194-195 (Sept. 1, 1966).

A broad-line proton magnetic resonance study of cobalt tetracarbonyl hydride, T. C. Farrar, F. E. Brinckman, T. D. Coyle, A. Davision, and J. W. Faller, Inorg. Chem. 6, 161-163 (1967).

A pycnometer for small volumes of liquids, S. Marantz and G. T. Armstrong, Chem.-Anal. 55, 114-115 (Oct. 1966).

Exactly solvable nonlinear relaxation processes, Systems of coupled harmonic oscillators, K. E. Shuler and G. H. Weiss, J. Chem. Phys. 45, No. 4, 1105-1110 (Aug. 15, 1966).

Flash photolysis of methane in the vacuum ultraviolet. I. Endproduct analysis, W. Braun, K. H. Welge, and J. R. MeNesby, J. Chem. Phys. 45, No. 7, 2650-2656 (Oct. 1, 1966).

Galvanic pitting in metallic coatings, F. Ogburn and M. Schlissel, Plating 54, No. 1, 54-62 (Jan. 1967)

Ion-molecule reactions in the condensed phase radiolysis of hydrocarbon mixtures. I. 2-methylbutane and 3-methylpentane, J. Am. Chem. Soc. 88, No. 24, 5701-5707 (Dec. 20, 1966).

Measurement of the surface area and the heats of wetting of dentin powders, G. M. Brauer, (Proc. Second Workshop on Adhesive Restorative Materials, Charlottesville, Va., December 1965), Book, Adhesive Restorative Dental Materials II, 203-223 (Department of Health, Education, and Welfare, Public Health Service, Washington, D.C. 1966).

Radiation-induced polymerization of hexafluoropropylene at high temperature and pressure, R. E. Lowry, D. W. Brown, and L. A. Wall, J. Polymer Sci. 4, Pt. A-1, No. 9, 2229-2239 (Sept. 1966).

Relaxation of moments derived from a master equation, K. E. Shuler and G. H. Weiss, J. Chem. Phys. 45, No. 4, 1110-1112 (Aug. 15, 1966).

The battle against corrosion, S. Lichtenstein, Compressed Air Mag. 71, No. 12, 12-13 (Dec. 1966).

Vibrational spectrum of $\mathrm{ClNF}_{2}$, J. J. Comeford, J. Chem. Phys. 45, No. 9, 3463-3465 (Nov. 1, 1966).

A new contribution - NBS and engineering standards, G. S. Gordon, Safety Standards XVI, No. 1, 3, 4, 24, and 25 (Jan.-Feb. 1967).

Additional thoughts on precision calibration of accelerometers, S. Edelman, Test Engineering and Management XVI, No. 5, 17, 18, 38, and 39 (Nov. 1966).

Air bath thermostat for use with absorption spectrophotometer, J. H. Gould, Rev. Sci. Instr. 37, No. 9, 1229-1231 (Sept. 1966).

Combination $\mathrm{RF}$ radiation and fluid pressure seal, M. B. Hall, N. T. Larsen, and W. E. Little, Proc. IEEE 54, No. 11, 15851586 (Nov. 1966).

Comparison of mass limiting two-phase flow in a straight tube and in a nozzle, D. K. Edmonds and R. V. Smith, Proc. Symp. Twophase Flow, University of Exeter, Devon, England, June 21-23, 1965, 1, 401-414 (University of Exeter, Devon, England, 1966).

Forces shaping the role of the architect, J. P. Eberhard, Proc. Second Architectural Center Conf., May 13-14, 1966, Boston, Mass., pp. 12 (Boston Architectural Center, Boston, Mass., May 1966).

Galvanic corrosion of metals in cementing materials, J. W. Pitts, Military Engr. 59, No. 387, 40-41 (Jan.-Feb. 1967).

Mass flowmeters in cryogenic service, W. J. Alspach, C. E. Miller, and T. M. Flynn, Proc. ASME Flow Measurement Conf., Pittsburgh, Pa., September 26-28, 1966, pp. 34-56 (1966). 
Technology for the city, J. P. Eberhard, Intern. Sci. Technol. 57, 18-29 (Sept. 1966).

The stress corrosion of metals, H. L. Logan, Book (John Wiley \& Sons, Inc., New York, N.Y., Nov. 1966).

A modified Monte-Carlo quacirature, S. Haber, Math. Compt. 20, No. 95, 361-368 (July 1966).

Electronic data processing in urban transportation planning, B. M. Levin and R. E. Schoefer (Proc. Second Annual Conference on Applications of E.D.P. Systems for State and Local Government, Apr. 1-2, 1966, New York, N.Y.). Book, The Large-Scale Public E.D.P. System: Its Problems and Prospects. pp. 169-177 (University of New York, N.Y., 1966).

Atomic standards of frequency and time, J. M. Richardson and J. F. Brockman, Phys. Teacher 4, No. 6, 247-256 (Sept. 1966).

Electrical standards and measurements, F. K. Harris, I. L. Cooter, B. L. Dunfee, W. P. Harris, F. L. Hermach, and C. Peterson, Electro-Technol. 97, 55-70 (Jan. 1967).

Time standards, J. M. Richardson, Book, Encyclopaedic Dictionary of Physics Supplementary I, 351-355 (Pergamon Press, Inc., New York, N.Y., 1966).

A new radiometric equation and its application, H. J. Kostkowski, Appl. Opt. 5, No. 12, 1959 (Dec. 1966).

An improved design for vacuum ultraviolet resonance lamps, A. M. Bass, Appl. Opt. 5, No. 12, 1967 (Dec. 1966).

Accommodation faculting in Fe-Ni martensitic transformation, R. P. Reed, Acta Met. 14, 1392-1394 (1966).

Acoustical thermometer and the National Bureau of Standards provisional temperature scale 2-20 (1965), H. Plumb and G. Cataland, Metrologia 2, No. 4, 127-139 (Oct. 1966).

Anomaly in Young's modulus and internal friction of $5 \mathrm{SrTiO}_{3} \cdot 3 \mathrm{La}_{2 / 3}$ $\mathrm{TiO}_{3}$ below $100{ }^{\circ} \mathrm{C}, \mathrm{R}$. W. Dickson, J. Am. Ceramic Soc. 49, No. 11, 628 (Nov. 1966).

Brownian motion models, R. J. Rubin, Summer Institute on Spectral Theory and Statistical Mechanics, Brookhaven National Laboratory, Upton, Long Island, N.Y. (July-Aug. 1965), Brookhaven Natl. Lab. Publ. PNL993 (T422), (Clearinghouse for Federal Scientific and Technical Information, Springfield, Va. 22151, 1966).

Chlorine $\mathrm{K} \beta$ x-ray emission spectra from several chlorinated hydrocarbon and fluorocarbon molecular gases, R. E. LaVilla and R. D. Deslattes, J. Chem. Phys. 45, No. 9, 3446-3448 (Nov. 1, 1966).

Comparison Langmuir probe and spectrometric electron temperature measurements, R. S. Powers, Jr., J. Appl. Phys. 37, No. 10, 3821-3826 (Sept. 1966).

Coriolis zeta constants and force field for osmium tetraoxide, I. W. Levin and S. Abramowitz, Inorg. Chem. 5, 2024-2026 (1966).

Correcting for astigmatism in the Czerny-Turner spectrometer and spectrograph, A. B. Shafer, Appl. Opt. 6, 159 (Jan. 1967).

Effect of sample thickness and operating voltage on the contrast of Kossel transmission photographs, H. Yakowitz, J. Appl. Phys. 37, No. 12, 4455-4458 (Nov. 1966).

Effects of a constant force on a Keplerian orbit, J. P. Vinti, Proc. Intern. Astronomical Union Symp. No. 25, Aug. 15-Sept. 3, 1964, Athens, Greece, pp. 355-362 (1966).

Erratum: Polycrystalline spin-wave theory of ferromagnetic resonance compared with the tilting experiment, A. S. Risley, E. G. Johnson, Jr., and H. E. Bussey, J. Appl. Phys. 37, No. 9, 3646 (Aug. 1966).

Flash photolysis of matrix-isolated cyanogen azide in solid nitrogen, L. J. Schoen, J. Chem. Phys. 45, No. 8, 2773-2776 (Oct. 15, 1966).

Molecular emission spectra in the soft x-ray region, R. D. Deslattes and R. E. LaVilla, Appl. Opt. 6, 39-42 (Jan. 25, 1967).

Newly measured and calculated wavelengths in the vacuum ultraviolet spectrum of neutral nitrogen, V. Kaufman and J. F. Ward, Appl. Opt. 6, No. 1, 43-46 (Jan. 1967).

Observation of the $\mathrm{D}^{1} \Delta \rightarrow x^{1} \Sigma+$ transition of $\mathrm{CO}$ in the vacuumultraviolet region, J. D. Simmons and S. G. Tilford, J. Chem. Phys. 45, No. 8, 2965-2968 (Oct. 15, 1966).

Observation of the superconducting energy gap in a semiconductor (GeTe), P. J. Stiles, L. Esaki, and J. F. Schooley, Physics Letters 23, No. 3, 206-207 (Oct. 17, 1966).

Optical constants of germanium, R. E. LaVilla and H. Mendlowitz, Appl. Opt. 6, No. 1, 61-68 (Jan. 1967).

Pyroelectric effect in bone and tendon, S. B. Lang, Nature 212, 704-705 (Nov. 12, 1966).
Radiance temperature at $6500 \AA$ of the graphite arc, R. D. Lee and E. Lewis, Appl. Opt. 5, No. 11, 1858 (Nov. 1966).

Reflection of soft x-rays by organic fibers, S. B. Newman, J. Appl. Polymer Sci. 10, 1929-1935 (1966).

Relation between refractive index and density of glasses resulting from annealing compared with corresponding relation resulting from compression, S. Spinner and R. M. Waxler, Appl. Opt. 5, No. 12, 1887-1889 (Dec. 1966).

Resolving power predictions from lens design data, O. N. Stavroudis, Appl. Opt. 6, No. 1, 129-135 (Jan. 1967).

Sodium-electron spin-exchange collisions, L. C. Balling, Phys. Rev. 151, No. 1, 1-6 (Nov. 4, 1966).

Some approximations to the Planck function in the intermediate region with applications in optical pyrometry, D. E. Erminy, Appl. Opt. 6, 107-117 (Jan. 1967).

Spectral radiance of a low current graphite arc, A. T. Hattenburg, Appl. Opt. 6, 95-99 (Jan. 1967).

Static theory of the giant quadrupole resonance in deformed nuclei, M. Danos, W. Greiner, and B. C. Kohr, Phys. Rev. 151, No. 3, 761-772 (Nov. 18, 1966).

Superconductivity in semiconducting $\mathrm{SrTIO}_{3}$, J. F. Schooley and W. R. Thurber (Proc. Intern. Conf. Physics of Semiconductors, Kyoto, Japan, Sept. 8-11, 1966), J. Phys. Soc. Japan 21, Paper XVI-2, 639-642 (Suppl. 1966).

The NBS photoelectric pyrometer and its use in realizing the international practical temperature scale above $1063{ }^{\circ} \mathrm{C}, \mathrm{R}$. D. Lee, Metrologia 2, No. 4, 150-162 (Oct. 1966).

The photodetachment cross section, electron affinity, and structure of the negative hydroxyl ion, L. M. Branscomb, Phys. Rev. 148, 11 (1966).

Thermal energy ion-neutral reaction rates. I. Some reactions of helium ions, F. C. Fehsenfeld, A. L. Schmeltekopf, P. D. Goldan, H. I. Schiff, and E. E. Ferguson, J. Chem. Phys. 44, No. 11, 40874094 (June 1, 1966).

Vibration spectra of yttrium and uranium hydrides by the inelastic scattering of cold neutrons, J. J. Rush, H. E. Flotow, D. W. Connor, and C. L. Thaper, J. Chem. Phys. 45, No. 10, 3817-3825 (Nov. 15, 1966).

Bonding adhesives and paints to treated concrete, W. C. Wolfe, CSI Monograph 9M1, Construction Specifier, pp. 1-8 (Aug. 1966).

Characteristics of the laser probe for spectrochemical analysis, S. D. Rasberry, B. F. Scribner, and M. Margoshes, Proc. XII Intern. Spectroscopy Colloquim, Exeter, England, 1965, pp. 336-339 (Hilger and Watts, London, England, 1966).

Chemiluminescence of $\mathrm{CH}$ in the $\mathrm{O}+\mathrm{C}_{2} \mathrm{H}_{2}$ reaction: Rotational relaxation and quenching, W. Brennen and T. Carrington, J. Chem. Phys. 46, No. 1, 7-18 (Jan. 1, 1967).

Corrosion's many faces, S. Lichtenstein, Southern Eng. 85, No. 1, 44-47 (Jan. 1967).

Dielectric constants of imperfect gases. III. Atomic gases, hydrogen, and nitrogen, R. H. Orcutt and R. H. Cole, J. Chem. Phys. 46, No. 2, 697-702 (Jan. 15, 1967).

Ellipsometric-potentiostatic studies of iron passivity. I. Anodic film growth in slightly basic solutions, J. Kruger and J. P. Calvert, J. Electrochem. Soc. 114, No. 1, 43-49 (Jan. 1967).

Formation of $\mathrm{NH}\left(c^{1} \Pi\right)$ and $\mathrm{NH}\left(\mathrm{A}^{3} \Pi_{i}\right)$ in the vacuum- $\mu \mathrm{v}$ photolysis of $\mathrm{HN}_{3}$, K. H. Welge, J. Chem. Phys. 45, No. 11, 4373-4374 (Dec. $1,1966)$.

Growth of calcite crystals, P. M. Gruzensky, (Proc. Intern. Conf. Crystal Growth, Boston, Mass., June 20-24, 1966), Crystal Growth, A Suppl. to J. Phys. Chem. Solids D-3, pp. 365-367 (Pergamon Press Inc., New York, N.Y., 1967).

Growth of calcium molybdate cyrstals by a temperature-gradient zone-melting technique, H. S. Parker and W. S. Brower, (Proc. Intern. Conf. Crystal Growth, Boston, Mass., June 20-24, 1966), Crystal Growth, A Suppl. to J. Phys. Chem. Solids E-12, pp. 489-491 (Pergamon Press Inc., New York, N.Y.. 1967).

Introduction of the Acheson medalist, R. G. Bates, J. Electro-chem Soc. 113, No. 12, 1-7 (Dec. 1966).

The crystal structure of twinned low-temperature lithium phosphate, C. Keffer, A. Mighell, F. Mauer, H. Swanson, and S. Block, Inorg. Chem. 6, No. 1, 119-125 (Jan. 1967).

The ionization constant of deuterium oxide from 5 to $50^{\circ}$, A. K. Covington, R. A. Robinson, and R. G. Bates, J. Phys. Chem. 70, 3820-3824 (1966).

The national standard reference data system, E. L. Brady, J. Chem. Doc. 7, No. 1, 6-9 (Feb. 1967). 
The optical and magnetic spectra of copper doped dichloro(1-10phenanthroline) zinc, G. F. Kokoszka, C. W. Reimann, and H. C. Allen, Jr., J. Phys. Chem. 71, No. 1, 121-126 (Jan. 1967).

Time-dependent behavior of activated molecules. High pressure unimolecular rate constant and mass spectra, F. H. Mies and M. Krauss, J. Chem. Phys. 45, No. 12, 4455-4468 (Dec. 15, 1966). Approximate normal emissivity spectra in the infrared at elevated temperatures of single-crystal and polycrystalline calcium fluoride, W. B. Fussell and J. C. Geist, Appl. Opt. 6, No. 1, 119-124 (Jan. 1967)

Electrodynamic vibration standard with a ceramic moving element, T. Dimoff, J. Acoust. Soc. Am. 40, No. 3, 671-676 (Sept. 1966). Interface kinetics and the stability of the shape of a solid sphere growing from the melt, S. R. Coriell and R. L. Parker, (Proc. Intern. Conf. Crystal Growth, Boston, Mass., June 20-24, 1966), Crystal Growth, A Suppl. to J. Phys. Chem. Solids, J-3, pp. 703708 (Pergamon Press Inc., New York, N.Y., 1967).

Mechanical properties of chemically strengthened glasses at high temperatures, M. J. Kerper and T. G. Scuderi, J. Am. Ceramic Soc. 40, No. 11, 613-618 (Nov. 1966).

On the solution of the Stefan problem for whisker growth, J. A. Simmons, H. Oser, and S. R. Coriell, (Proc. Intern. Conf. Crystal Growth, Boston, Mass., June 20-24, 1966), Crystal Growth, A Suppl. to J. Phys. Chem. Solids C-8, pp. 255-264 (Pergamon Press Inc., New York, N.Y., 1967).

Procedures for precise determination of thermal radiation properties, J. C. Richmond, G. J. Kneissl, D. L. Kelley, and F. J. Kelly, Tech. Report AFML-TR-66-302 (Air Force Materials Laboratory, Air Force Systems Command, Wright-Patterson Air Force Base, Ohio, Aug. 1966).

Relation of fracture stress to the fracture pattern for glass rods of various diameters, M. J. Kerper and T. G. Scuderi, Am. Ceramic Soc. Bull. 45, No. 12, 1065-1066 (Dec. 7, 1966).

The nucleation of $\mathrm{Hg}$ on $\mathrm{W}$ as observed by field-emission microscopy, S. C. Hardy (Proc. Intern. Conf. Crystal Growth, Boston, Mass., June 20-24, 1966), Crystal Growth, A Suppl. to J. Phys. Chem. Solids C-13, pp. 287-293 (Pergamon Press Inc., New York, N.Y., 1967).

Thermal correction and crystal growth in horizontal boats, flow pattern, velocity measurement, and solute distribution, H. P. Utech, W. S. Brower, and J. G. Early (Proc. Intern. Conf. Crystal Growth, Boston, Mass., June 20-24, 1966), Crystal Growth, A Suppl. to J. Phys. Chem. Solids B-29, pp. 201-205 (Pergamon Press Inc., New York, N.Y., 1967).

Wind effect on preexisting waves, G. Kulin, Proc. 1965 ASCE Conf. Coastal Engineering, Santa Barbara, Calif., October 1965, ch. 16, pp. 369-389 (American Society of Civil Engineers, 1966).

Physiological optics at the National Bureau of Standards, D. B. Judd, Appl. Opt. 6, No. 1, 13-26 (Jan. 1967).

The new tungsten-filament lamp standards of total irradiance, R. Stair, W. E. Schneider, and W. B. Fussell, Appl. Opt. 6, No. 1, 101-105 (Jan. 1967).

The role of the National Bureau of Standards in the establishment of measurement capability at the state level, T. M. Stabler, Instr. Soc. Am. Preprint 16.1-3-66, pp. 1-3 (Oct. 24-27 1966).

A vacuum ultraviolet flash photolysis apparatus, W. Braun, A. M. Bass, and A. E. Ledford, Jr., Appl. Opt. 6, No. 1, 47-49 (Feb. 2, 1967).

Analysis of the $\alpha, \beta$, and $\gamma$ relaxations in polychlorotrifluoroethylene and polyethylene: dielectric and mechanical properties, J. D. Hoffman, G. Williams, and E. Passaglia, J. Polymer Sci. Pt. C, No. 14, 173-235 (1966)

Calculated heats of dilute solid solution among the alkali halides other than cesium salts, T. B. Douglas, J. Chem. Phys. 45, No. 12, 4571-4585 (Dec. 15, 1966).

Concepts, terminology, and notation for optical modulation, C. S. McCamy, Photo. Sci. Eng. 10, No. 6, 314-325 (Nov.-Dec. 1966).

Condensation of dry air on a liquid hydrogen cooled surface in the pressure range $10^{-3}$ to 10 torr (Knudsen number of $10^{-4}$ to 1 ), J. Hord, Cryogenics 6, No. 5, 285-293 (Oct. 1966).

Elastic properties of NiTi as a function of temperature, S. Spinner and A. G. Rozner, J. Acoust. SQc. Am. 40, No. 5, 1009-1015 (Nov. 1966).

Glass research at the National Bureau of Standards, G. W. Cleek, Glass Ind. 47, No. 12, 663-669 (Dec. 1966).
Instrumental aspects of synchrotron XUV spectroscopy, R. P. Madden, D. L. Ederer, and K. Codling, Appl. Opt. 6, No. 1, 31-38 (Jan. 1967).

Inversion temperatures and pressures for cryogenic gases and their mixtures, R. D. Gunn, P. L. Chueh, and J. M. Prausnitz, Cryogenics 6, No. 6, 324-329 (Dec. 1966).

Matrix elements of general potentials in the harmonic-oscillator representation, R. M. Wilcox, J. Chem. Phys. 45, No. 9, 33123316 (Nov. 1, 1966).

Measurement and calculation of CU II, Ge II, Si II, and CI vacuumultraviolet lines, V. Kaufman and J. F. Ward, J. Opt. Soc. Aṃ. 56, No. 11, 1591-1597 (Nov. 1966).

Measurements of relative oscillator strengths of some C II multiplets, J. R. Roberts and K. L. Eckerle, Phys. Rev. 153, No. 1, 87-90 (Jan. 1967).

Moisture permeation of leather and plastics used in shoes, J. R. Kanagy, J. Am. Leather Chemists' Assoc. Tech. Note LXII, No. 2, 115-122 (Feb. 1967).

Note on the variation of the results of the Mullen burst test over the area of a hide, J. R. Kanagy, J. Am. Leather Chemists' Assoc. Tech. Note LXII, No. 1, 63-67 (Jan. 1967).

Recent advances in excitation of atomic spectra, M. Margoshes, Proc. XII Intern. Spectroscopy Colloquium, Exeter, England, 1965, pp. 26-42 (Hilger and Watts, London, England, 1966).

The dispersion of distributions derived from folding simple distributions, R. A. Schrack, Nucl. Instr. Methods 45, No. 2, 319-321 (1966).

The effect of a two-dimensional roughness element on boundarylayer transition, P. S. Klebanoff, (Proc. Eleventh Intern. Congress Applied Mechanics, Munich, Germany, 1964), Book, Applied Mechanics, ed. H. Gotler, pp. 803-805 (Springer-Verlag Berlin, Germany, 1966).

The forbidden $\mathrm{I}^{1} \Sigma^{-}-\mathrm{X}^{1} \Sigma^{+}$absorption bands of carbon monoxide, G. Herzberg, J. D. Simmons, A. M. Bass, and S. G. Tilford, Can. J. Phys. 44, 3039-3045 (1966).

The National Bureau of Standards and its contributions to geophysics, D. Baker, Trans. Am. Geophys. Union 17, No. 4, 563-568 (Dec. 1966).

Two-quantum photoionization of $\mathrm{Cs}$ and $\mathrm{I}^{-}$, J. L. Hall, IEEE J. Quantum Electron. QE-2, No. 9, 361-363 (Sept. 1966).

Determination of the composition of complexes and their instability constant by calorimetry. II. The complex in fused potassium chloride and cadmium chloride, W. H. Metzger, Jr., A. Brenner, and H. I. Salmon, J. Electrochem. Soc. 114, No. 2, 131-138 (Feb. 1967).

Influence of paramagnetic resonance on the static susceptibility. The lattice-bath relaxation time of neodymium ethyl sulfate, G. A. Candela and R. E. Mundy, J. Chem. Phys. 46, No. 1, 47-54 (Jan. 1, 1967).

Measurement of optical constants: optical constants of liquid mercury at $5461 \AA$, L. E. Smith and R. R. Stromberg, J. Opt. Soc. Am. 56, No. 11, 1539-1542 (Nov. 1966).

Nitrogen on rhenium observed with the field emission microscope, R. Klein and J. W. Little, Surface Sci. 6, No. 2, 193-207 (Feb. 1967).

Nitrogen sorption measurements and surface areas of hardened cement pastes, C. M. Hunt, Highway Research Board Symposium on Structure of Portland Cement Paste, Washington, D.C., January 1965, Highway Research Board Special Report 90, 112122 (1966).

Nonstoichiometric Al5-type phases in the systems Cr-Pt and Cr-Os, R. M. Waterstrat and E. C. van Reuth, Trans. Met. Soc. AIME 236, No. 8, 1232-1233 (Aug. 1966).

Pressures exerted on complete dentures during swallowing, M. Ohashi, J. B. Woelfel, and G. C. Paffenbarger, J. Am. Dental Ássoc. 73, No. 3, 625-630 (Sept. 1966).

Production and reaction of atomic fluorine in solids. Vibrational and electronic spectra of the free radical HNF, M. E. Jacox and D. E. Milligan, J. Chem. Phys. 46, No. 1, 184-191 (Jan. 1, 1967).

Proposal for the practical measurement of $\mathrm{pH}$ in amphiprotic and mixed solvents, R. G. Bates, Intern. Union Pure Appl. Chem. Info. Bull. No. 26, 50-54 (Aug. 1966).

Recent advances in U.S.A. research on dental amalgams and possible applications, G. C. Paffenbarger, Intern. Dental J. 16, No. 4, 450-465 (Dec. 1966). 
Structural interpretation of immiscibility in oxide systems: IV, Occurrence, extent, and temperature of the monotectic, E. M. Levin, J. Am. Ceram. Soc. 50, No. 1, 29-38 (Jan. 1967).

The system $\mathrm{Sc}_{2} \mathrm{O}_{3}-\mathrm{B}_{2} \mathrm{O}_{3}$, E. M. Levin, J. Am. Ceramic Soc. 50, No. 1, 53-54 (Jan. 1967).

Analysis and computer simulation of the production and distribution systems of a tufted carpet mill, J. A. Yurow, J. End. Eng. XVIII, No. 1, 135-140 (Jan. 1967).

Building code viewpoints, A. A. Bates (Building Research Institute Fall Conf., Codes Session, Washington, D. C., Nov. 16, 1966), J. Bldg. Res. Inst. 4, No. 1, 48-49 (Jan-Feb. 1967).

Earth temperature and thermal diffusivity at selected stations in the United States, T. Kusuda and P. R. Achenbach, ASHRAE Trans. 71, Pt. 1, 61-75 (Jan. 25-28, 1965).

Micrometer u-tube manometers for medium-vacuum measurements, A. W. Thomas and J. L. Cross, J. Vacuum Sci. Technol. 4, No. 1, 1-5 (Jan.-Feb. 1967).

Outdoor air psychrometric criteria for summer ventilation of protective shelters, T. Kusuda and P. R. Achenbach, ASHRAE Trans. 71, Pt. 1, 76-87 (Jan. 25-28, 1965).

The city as a system, J. P. Eberhard, Proc. Mid-American Conf. Design, Kansas City, Mo., March 30-31, 1966, pp. 25-30 (Midwest Research Institute, Kansas City, Mo., 1966).

The RF connector, R. C. Powell, Microwave J. 10, No. 3, 69 (Feb. 1967).

Processing of numerical test data, J. Mandel and T. W. Lashof, Book, Testing of Polymers, ed. J. V. Schmitz, 2, sh. 2, 33-82 (Interscience Publ. New York, N.Y., 1966).

The design of a federal statistical data center, E. Glaser, D. Rosenblatt, and M. K. Wood, Am. Stat. 21, No. 1, 12-20 (Feb. 1967).

Time-dependent behavior of an incompressible elastic fluid. Some homogeneous deformation histories, B. Bernstein, Acta Mechanica II, No. 4, 329-354 (1966).

Optimum allocation of calibration errors, E. L. Crow, Ind. Quality Control 23, No. 5, 215-219 (Nov. 1966).

Adsorption of polymers, R. R. Stromberg, Book, Treatise of Adhesives and Adhesion, Vol. 1, Theory, ch. 3, 69-118 (Marce] Dekkers Inc., New York, N.Y., 1967).

Avalanche radiation from the bulk of long, thin, forward-biased $p^{+}-p-n^{+}$silicon diodes, G. G. Harman, Appl. Phys. Letters 9, No. 5, 207-209 (Sept. 1, 1966).

A study of the angular and energy distributions of radiation at small distances from a point source of gamma rays or neutrons, C. Eisenhauer, Nucl. Sci. Eng. 27, 240-251 (1967).

A survey of second breakdown, H. A. Schafft and J. C. French, IEEE Trans. Electron. Devices ED-13, No. 8-9, 613-618 (Aug.Sept. 1966).

Baffled piston radiator: expansion of potential in far, paraxial field, M. Greenspan, J. Acoust. Soc. Am. 40, No. 1, 251-252 (July 1966).

Cerous magnesium nitrate: a magnetic temperature scale $0.002-2{ }^{\circ} \mathrm{K}$, R. P. Hudson and R. S. Kaeser, Physics 3, No. 2, 95-113 (1967).

Definition of temperature in the kinetic theory of dense gases, L. S. Garcia-Colin and M. S. Green, Phys. Rev. 150, No. 1, 153158 (Oct. 7, 1966).
Divergence in the density expansion of the transport coefficients of a two-dimensional gas, J. V. Sengers, Phys. Fluids 9, No. 9 , 1685-1696 (Sept. 1966).

Effective charge carrier lifetime in silicon $p-i-n$ junction detectors, J. A. Coleman and L. J. Swartzendruber, (Proc. 10th Scintillation and Semiconductor Counter Symp., Washington, D.C., Mar. 23-24, 1966), IEEE Trans. Nucl. Sci. NS-13, No. 3, 240-244 (June 1966).

Elastic constants of single crystal $\mathrm{UO}_{2}$ at $25{ }^{\circ} \mathrm{C}, \mathrm{J}$. B. Wachtman, Jr., M. L. Wheat, H. J. Anderson, and J. L. Bates, J. Nuclear Mater. 16, 39-4l (1965).

Fermi controlled recombination as a junction design factor in $\mathrm{GaAs}$ laser diodes, N. N. Winogradoff and H. K. Kessler, Int. J. Electronics 21, No. 4, 329-335 (1966).

Ferrimagnetic resonance low-field effects in rod samples, L. B. Schmidt, R. D. Harrington, and W. E. Case, Proc. IEEE 55, No. 1, 120-121 (Jan. 1967).

Kinetics of growth of multicomponent chains, J. I. Lauritzen, Jr., E. A. DiMarzio, and E. Passaglia, J. Chem. Phys. 45, No. 12, 4444-4454 (Dec. 15, 1966).

Lack of uniqueness in the international practical temperature scale above the gold point, H. J. Kostkowski, Metrologia 3, No. 1, 28-29 (Jan. 1967).

Magnetization of iron for magnetometer calibrations, W. E. Case and R. S. Harrington, Proc. IEEE 54, No. 12, 2004-2005 (Dec. 1966).

Mechanical relaxation in polychlorotrifluoroethylene, J. M. Crissman and E. Passaglia, J. Polymer Sci. Pt. C, No. 14, 237-245 (1966).

Nuclear hexadecapole interactions, R. J. Mahler, Phys. Rev. 152, No. 1, 325-330 (Dec. 2, 1966).

Optical power increase in GaAs laser diodes coated with reflecting aluminum silicone mixture, H. K. Kessler, Proc. IEEE Letter 55, No. 1,99-100 (Jan. 1967).

Radiative recombination within a space-charge region in a semiconductor, N. N. Winogradoff, J. Appl. Phys. 37, No. 10, 39163917 (Sept. 1966).

Solid-vapour equilibrium in the system neon-methane, M. J. Hiza and A. J. Kidnay, Cryogenics 6, No. 6, 348-354 (Dec. 1966).

Spin-relaxation effects on the EPR spectrum of gaseous S-state atoms, R. L. Brown and W. Brennen, J. Chem. Phys. 46, No. 1, 385-386 (Jan. 1, 1967).

Surface aspects of the thermal degradation of GaAs $p$ - $n$ junction lasers and tunnel diodes, H. Kessler and N. N. Winogradoff, IEEE Trans. Electron. Devices ED-13, No. 10, 688-691 (Oct. 1966).

* Publications for which a price is indicated are available by purchase from the Superintendent of Documents, U.S. Government Printing Office, Washington, D.C. 20402 (foreign postage, one-fourth additional). The NBS nonperiodical series are also available from the Clearinghouse for Federal Scientific and Technical Information, Springfield, Va. 22151. Reprints from outside journals and the NBS Journal of Research may often be obtained directly from the authors. 